\title{
Impaired Interneuron Development in a Novel Model of Neonatal Brain Injury
}

\author{
Helene Lacaille, ${ }^{1}$ Claire-Marie Vacher, ${ }^{1}$ Dana Bakalar, ${ }^{1}$ Diaqi J. O’Reilly, ${ }^{1,2}$ Jacquelyn Salzbank, ${ }^{1,2}$ and
} Anna A. Penn 1,2,3

https://doi.org/10.1523/ENEURO.0300-18.2019

${ }^{1}$ Center for Neuroscience, Children's National Health System, Washington, DC 20010, ${ }^{2}$ Institute for Biomedical Sciences, George Washington University, Washington, DC 20037, and ${ }^{3}$ Fetal Medicine Institute, Neonatology, Children's National Health System, Washington, DC 20010

\begin{abstract}
Prematurity is associated with significantly increased risk of neurobehavioral pathologies, including autism and schizophrenia. A common feature of these psychiatric disorders is prefrontal cortex (PFC) inhibitory circuit disruption due to GABAergic interneuron alteration. Cortical interneurons are generated and migrate throughout late gestation and early infancy, making them highly susceptible to perinatal insults such as preterm birth. Term and preterm PFC pathology specimens were assessed using immunohistochemical markers for interneurons. Based on the changes seen, a new preterm encephalopathy mouse model was developed to produce similar PFC interneuron loss. Maternal immune activation (MIA; modeling chorioamnionitis, associated with $85 \%$ of extremely preterm births) was combined with chronic sublethal hypoxia $(\mathrm{CSH}$; modeling preterm respiratory failure), with offspring of both sexes assessed anatomically, molecularly and neurobehaviorally. In the PFC examined from the human preterm samples compared to matched term samples at corrected age, a decrease in somatostatin (SST) and calbindin (CLB) interneurons was seen in upper cortical layers. This pattern of interneuron loss in upper cortical layers was mimicked in the mouse PFC following the combination of MIA and $\mathrm{CSH}$, but not after either insult alone. This persistent interneuron loss is associated with postnatal microglial activation that occurs during $\mathrm{CSH}$ only after MIA. The combined insults lead to long-term neurobehavioral deficits which parallel human psychopathologies that may be seen after extremely preterm birth. This new preclinical model supports a paradigm in which specific cellular alterations seen in preterm encephalopathy can be linked with a risk of neuropsychiatric sequela. Specific interneuron subtypes may provide therapeutic targets to prevent or ameliorate these neurodevelopmental risks.
\end{abstract}

Key words: hypoxia; inflammation; interneurons; prematurity; psychiatric disorders

\section{Significance Statement}

Growing evidence suggests that a common component of psychiatric disorders is damage to inhibitory neurons. In the frontal lobe, these neurons continue to develop during late gestation and infancy, predisposing preterm survivors to neurobehavioral disorders and/or cognitive impairment. Preventing neuronal damage depends on having accurate models of preterm brain injury with well-defined outcome measures that can be examined in both small animals and humans. In this study, interneuron number were assessed in term and preterm human frontal brain tissues and in a novel multifactorial model that combines prenatal inflammation with postnatal hypoxia resulting in long-term inhibitory neuron loss. This new model was validated through anatomic and functional assessments that directly translate to human measures. 


\section{Introduction}

Dysfunction of the prefrontal cortex (PFC) underlies a number of deficits associated with psychiatric disorders, particularly their cognitive and social components (Sugranyes et al., 2011). A common feature of these psychiatric disorders is a disruption of PFC inhibitory circuits, mediated by developmental alterations of GABA interneurons (Marin, 2012). Interneuron loss, misplacement, and dysmaturation characterize these disorders (Gogolla et al., 2009; Meechan et al., 2009; Takano, 2015; Filice et al., 2016; Hashemi et al., 2017). Specifically, GABAergic network alteration in the Brodmann area 9 (BA9; dorsolateral $\mathrm{PFC}$ ), a region involved in working memory and social cognition, may account for specific cognitive deficits of these disorders (Tooney and Chahl, 2004; Samaco et al., 2005; Fatemi et al., 2009; Habl et al., 2012; Hashemi et al., 2017).

GABA progenitor cells proliferate in the fetal brain (at least through 35 weeks of gestation; Arshad et al., 2016) and then migrate to the frontal lobes and mature during infancy (Paredes et al., 2016), leaving these interneurons precursors highly susceptible to perinatal insults. A correlation between prematurity, GABA concentration and abnormal functional connectivity has been demonstrated in the BA9 (Kwon et al., 2014), raising the possibility that alterations in interneuron number or function may contribute to increase the risk of later neurodevelopmental psychopathology associated with preterm birth (Johnson and Marlow, 2011).

Preterm birth (delivery before 37 weeks of gestation) is a multifactorial syndrome. Chorioamnionitis occurs in up to $85 \%$ of extremely preterm births and is strongly associated with an increased risk of spontaneous preterm delivery (Blencowe et al., 2013). After preterm birth, additional insults such as respiratory failure can increase the risk of long-term impairments, including disorders of executive functioning, autism, and schizophrenia (Adams-

Received August 1, 2018; accepted January 3, 2019; First published January 31, 2019.

The authors declare no competing financial interests.

Author contributions: H.L., C.-M.V., and A.A.P. designed research; H.L. performed research; H.L., A.A.P., C.-M.V., D.B., J.J.O., and J.S. analyzed data; H.L. and A.A.P. wrote the paper.

This work was supported by the National Institutes of Health Grant R01HD092593, the District of Columbia Intellectual Developmental Disabilities Research Center Grant U54HD090257, the Cerebral Palsy Alliance Research Foundation, the Children's National Board of Visitors, and the Fetal Medicine Institute, Washington DC.

Acknowledgements: We thank Dr. J. Scafidi and Dr. L. Wang for neurobehavioral equipment and testing assistance; Eresha Bluth and Janine Burgess for expert assistance; and Dr. V. Gallo and Dr. M. Shoykhet for their constructive criticism of this manuscript. We also thank the contribution of families to the NIH NeuroBioBank, as well as J. Cottrell (NIH NeuroBioBank), who assisted us throughout the process of human tissue selection.

Correspondence should be addressed to Anna A. Penn at apenn@childrensnational.org.

https://doi.org/10.1523/ENEURO.0300-18.2019

Copyright (C) 2019 Lacaille et al.

This is an open-access article distributed under the terms of the Creative Commons Attribution 4.0 International license, which permits unrestricted use, distribution and reproduction in any medium provided that the original work is properly attributed.
Chapman and Stoll, 2006; Arpino et al., 2010; Meldrum et al., 2013; Knuesel et al., 2014; Lombardo et al., 2017).

Understanding interneuron alterations after preterm birth can contribute to a better comprehension of the perinatal environment's impact on psychiatric disorders. In this study, examination of a set of human preterm and term postmortem samples demonstrated decreased density of specific PFC interneuron subpopulations. To investigate this finding of persistent interneuron loss, a novel multi-insult mouse model was then developed, using both prenatal maternal immune activation (MIA) and postnatal chronic sublethal hypoxia $(\mathrm{CSH})$, designed to capture the type and timing of common perinatal physiologic insults. Prior models have induced early MIA resulting in limited deficits of cortical interneurons (Carpentier et al., 2013; Canetta et al., 2016). Likewise, postnatal insults during the first two weeks of rodent life, such as hypoxiaischemia or $\mathrm{CSH}$, have been used to mimic white matter abnormalities that develop in preterm infants (Mayoral et al., 2009; Salmaso et al., 2014; Scafidi et al., 2014; Zonouzi et al., 2015). Limited alterations of interneuron numbers (Fagel et al., 2009) or delayed interneuron maturation (Komitova et al., 2013) have been described after these postnatal insults, but these changes do not recapitulate the human pathology depicted here. Rather, unlike embryonic MIA or postnatal CSH alone, the combination of insults significantly disrupts the density of mature interneurons in the PFC, mimicking the cellular alterations seen in the samples from extremely preterm neonates examined here- and induces specific cognitive deficits.

This multi-hit protocol is proposed as a novel preclinical model to decipher the cellular and physiologic mechanisms underlying the deficits seen in preterm survivors exposed to inflammation and hypoxia that may make them vulnerable to later neuropsychiatric disorders.

\section{Materials and Methods}

\section{Study approval}

All animal procedures were performed in accordance with the Children's National Institutional Animal Care and Use Committee (\#00030312).

\section{Human samples}

Human samples were obtained from the NIH NeuroBioBank at University of Maryland, Baltimore, MD (ID \#709). Donors consisted of corrected age preterm and matched term infants, excluding those with major congenital anomalies, or known genetic diagnoses and those with meningitis or stroke as cause of death. Sex, gestational weeks, absolute age (postnatal age), and corrected age are shown in Table 1. BA9 formalin-fixed brain samples were cut into $0.5-\mathrm{cm}$-thick coronal slices and preserved in $10 \%$ neutral buffered formalin; matched frozen tissues were preserved at $-80^{\circ} \mathrm{C}$.

\section{Animals}

Experimental mice were produced by a heterozygous breeding scheme in which GAD65-GFP transgenics (C57BL/6 background; obtained from Dr. Vittorio Gallo, 
Table 1. List of donors (from NIH NeuroBioBank, University of Maryland, Baltimore, MD)

\begin{tabular}{|c|c|c|c|c|c|}
\hline \multicolumn{6}{|c|}{ Preterm infants } \\
\hline $\begin{array}{l}\text { Accession } \\
\text { number }\end{array}$ & Sex & $\begin{array}{l}\text { Gestational } \\
\text { weeks }\end{array}$ & $\begin{array}{l}\text { Absolute } \\
\text { age (months) }\end{array}$ & $\begin{array}{l}\text { Corrected } \\
\text { age (months) }\end{array}$ & Cause of death \\
\hline-1224 & M & 31 & 1.3 & -1 & Sudden unexplained death in infancy \\
\hline 437 & M & 28 & 3.3 & 0.3 & Sudden unexplained death in infancy \\
\hline 934 & M & 27 & 4.5 & 1.3 & Sudden unexplained death in infancy \\
\hline 1325 & $\mathrm{~F}$ & 25 & 6.1 & 2.3 & Sudden unexplained death in infancy \\
\hline 1487 & $\mathrm{~F}$ & 29 & 2.1 & -0.6 & Prematurity with complications \\
\hline 4364 & M & 27 & 4.8 & 1.6 & Prematurity, pneumonia \\
\hline 4373 & $\mathrm{~F}$ & 34 & 3.3 & 1.8 & Methicillin susceptible Staphylococcus \\
\hline 4389 & $\mathrm{~F}$ & 34 & 2.6 & 1.1 & Positional asphyxia \\
\hline 4416 & $\mathrm{~F}$ & 26 & 4.7 & 1.2 & Asphyxia, prematurity \\
\hline 4417 & M & 28 & 2.4 & -0.6 & Undetermined, hepatic stenosis, prematurity \\
\hline 5708 & $\mathrm{~F}$ & 29 & 5.2 & 2.5 & Viral syndrome with focal acute pneumonia \\
\hline 5716 & M & 29 & 3.2 & 0.5 & Sudden unexplained death in infancy \\
\hline 5754 & M & 33 & 5 & 3.2 & Sudden unexplained death in infancy \\
\hline 5843 & M & 34 & 3.3 & 1.8 & Sudden unexplained death in infancy \\
\hline \multicolumn{6}{|c|}{ Term control infants } \\
\hline $\begin{array}{l}\text { Accession } \\
\text { number }\end{array}$ & Sex & $\begin{array}{l}\text { Gestational } \\
\text { weeks }\end{array}$ & $\begin{array}{l}\text { Absolute } \\
\text { age (months) }\end{array}$ & $\begin{array}{l}\text { Corrected } \\
\text { age (months) }\end{array}$ & Cause of death \\
\hline 4353 & M & 40 & 1.1 & 1.1 & Positional asphyxia \\
\hline 4355 & M & 38 & 2.7 & 2.2 & Prone sleep position and excessive bedding \\
\hline 4375 & $\mathrm{~F}$ & 40 & 0.1 & 0.1 & Positional asphyxia \\
\hline 4381 & $\mathrm{~F}$ & 40 & 3 & 3 & Probable asphyxia \\
\hline 4383 & $\mathrm{~F}$ & 40 & 2.5 & 2.5 & Probable overlay \\
\hline 4391 & M & 40 & 0.9 & 0.9 & Asphyxia due to co-sleeping \\
\hline 4402 & M & 39 & 2.2 & 2 & Co-sleeping \\
\hline 4412 & M & 40 & 2.2 & 2.2 & Sudden unexplained infant death \\
\hline 4414 & $\mathrm{~F}$ & 37 & 1.3 & 0.5 & Sudden unexpected infant death with co-sleeping \\
\hline 4420 & M & 40 & 2.1 & 2.1 & Positional asphyxia \\
\hline 5658 & M & 38 & 1.4 & 0.9 & Sudden unexplained death in infancy \\
\hline 5761 & $\mathrm{~F}$ & 38 & 1.1 & 0.6 & Sudden unexplained death in infancy \\
\hline 5886 & M & 40 & 1.5 & 1.5 & Sudden unexplained death in infancy \\
\hline
\end{tabular}

generated from Dr. Gabor Szabo; López-Bendito et al., 2004) were crossed to C57BL/6 mice. For time pregnant mating, male and female pairs were housed overnight, with the following day designated as embryonic day (E)0.5. The day of birth was designated as postnatal day (P)0. For all experiments described here, embryos and postnatal pups of both sexes were included. Each experimental group contained pups from at least two litters.

\section{MIA and CSH}

Mild, late MIA was induced using $150 \mu \mathrm{g} / \mathrm{kg}$ of lipopolysaccharide (LPS; L6529, from Escherichia coli O55:B5, Millipore Sigma), administered to the pregnant dam intraperitoneally on both E15.5 and E16.5. After delivery, dams and litters were housed in $10.9 \%$ oxygen from P3 to P10 to produce $\mathrm{CSH}$, with control litters housed in the same room outside of the hypoxia chamber. No adverse effects of hypoxia were noted on dams or pups, except for mild growth restriction that resolved over the first postnatal month (Salmaso et al., 2015). Four experimental groups were studied: mice treated with saline and reared under normoxia (MIA-/CSH-), mice subjected to MIA and reared under normoxia (MIA+/CSH-), mice treated with saline and reared under $\mathrm{CSH}$ (MIA-/CSH+), and mice subjected to $\mathrm{MIA}$ and reared under $\mathrm{CSH}(\mathrm{MIA}+/ \mathrm{CSH}+)$. Mice from multiple litters were randomly assigned to these groups and groups were balanced for litter size and sex.

\section{Immunohistochemical procedure}

\section{Human tissue}

Formalin-fixed tissues were cryoprotected in a $30 \%$ sucrose solution and embedded in Tissue-Tek O.C.T. Compound (Sakura Finetek). Blocks were cut into 25- $\mu \mathrm{m}$ thick sections on a cryostat and mounted on Superfrost Plus (ThermoFisher) glass slides. Frozen sections were allowed to equilibrate to room temperature for $2 \mathrm{~h}$ before staining.

\section{Mouse tissue}

Embryonic brains were obtained after euthanasia of the dam by $\mathrm{CO}_{2}$ asphyxiation followed by cerebral dislocation; brains were quickly dissected in $1 \times$ PBS and transferred to $4 \%$ paraformaldehyde (PFA). Postnatal mice were perfused at P10 or P30 with $1 \times$ PBS/4\% PFA, and brains were postfixed in 4\% PFA for $24 \mathrm{~h}$ and transferred into $30 \%$ sucrose in $1 \times$ PBS. Brains were sectioned into coronal $40-\mu \mathrm{m}$-thick sections with a sliding microtome before immunolabeling.

\section{Procedure}

Tissue sections were rinsed in PBS-Triton X-100 0.3\% (PBS-T) then blocked in PBS-T with 10\% normal donkey serum (NDS) followed by overnight incubation at $4^{\circ} \mathrm{C}$ in PBS-T-10\% NDS with primary antibodies: BrdU (1:500, Abcam, ab6326), calbindin (CLB; 1:1000, Swant Marly, Cb300 or Cb38), calretinin (CRT; 1:1000, Millipore Sigma 
AB1550), cleaved-caspase 3 (1:500, Cell Signaling Technology, Asp175), CD68 (1:300, Bio-Rad, MCA1957GA), Gad65-67 (1:200 Santa Cruz Biotechnology sc-365180), Gad67 (1:100, Millipore Sigma MAB5406), GFP (1:500, Abcam, Ab13970), Iba1 (1:500, Wako Chemicals, 01919741), Ki67 (1:500, Abcam, ab15580), NeuN (1:500, Abcam, ab177487), neuropetide $Y$ (1:500, Immunostar, 22940), parvalbumin (PV; 1:1000, Millipore Sigma, P3088), somatostatin (SST; 1:300, Santa Cruz Biotechnology, sc7819), reelin (RLN; 1:300, R\&D Systems, AF3820), and VIP (1:1000, Immunostar, 20077). For secondary detection, appropriately matched Alexa Fluor-conjugated secondary antibodies (1:500, ThermoFisher) were incubated 90 min in PBS-T at room temperature. For all groups studied, dividing cells were detected with bromodeoxyuridine (BrdU, Roche) injected at E15.5 intraperitoneally at $50 \mathrm{mg} / \mathrm{kg}$. For BrdU staining, a DNA denaturation step was performed by incubating the sections in $2 \mathrm{~N} \mathrm{HCl}$ for $30 \mathrm{~min}$ at $45^{\circ} \mathrm{C}$ before the primary antibody incubation. Sections were incubated with DAPI, mounted in Fluoromount G (ThermoFisher) and coverslipped before confocal examination (Olympus FV1000).

\section{Quantification}

For human sections, the cell density was assessed in the upper layers (ULs), lower layers (LLs), and the subcortical white matter (SWM) of BA9 and expressed in cells/ $\mathrm{mm}^{2}$. Cortical layering was determined with DAPI counterstaining. For mouse tissues, results from four sections per animal and five to six animals per group were average and the number of cells in each cortical subregion was expressed as density of cells $/ \mathrm{mm}^{3}$. Cortical layering was determined with DAPI counterstaining (Skorput et al., 2015). The delineation between the anterior cingulate cortex (ACC) and the prelimbic area $(P L)$ is based on the Allen Brain Atlas. Cell quantification was performed using the Imaris-Bitplane software. All counts were performed blind to condition.

\section{Real-time PCR (RT-PCR)}

Human tissue

BA9 tissues were homogenized in TRIzol Reagent (ThermoFisher, 15596018); total RNA was extracted with the RNeasy Mini kit (QIAGEN, 74104).

\section{Mouse tissue}

Cerebral cortices were collected in RNA later (QIAGEN, 76106); total RNA was extracted with the PARIS kit (ThermoFisher, AM1921) and quantified with a Nanodrop ND2000C (ThermoFisher).

\section{Procedure}

A total of $1 \mu \mathrm{g}$ of RNA was used to make cDNA with the iScript cDNA Synthesis kit (Bio-Rad, 1708891). All primer pairs were designed and validated in-house for efficiency and specificity. RT-PCR experiments were performed on cDNA samples in presence of SsoAdvanced Universal SYBR Green Supermix (Bio-Rad, 1725271) with specific primers at $100 \mathrm{nM}$ using the $\mathrm{ABI}$ Prism 7500 Sequence Detection System, ThermoFisher). The cDNA-generated signals for target genes were internally corrected with transferrin receptor protein 1 (tfrc) for human tissues and phosphoglycerate kinase 1 (pgk1) for mouse tissues. The regulation was determined with the $2^{-\Delta \Delta C q}$ method.

\section{Western blotting}

Human samples were homogenized in RIPA lysis buffer with proteinase inhibitors (Santa Cruz Biotechnology, sc24948). Protein extracts, $40 \mu \mathrm{g}$ per lane, were loaded onto $4-20 \%$ gradient gels (NuSep Inc, NB10-420). Gels were electrotransfered to a $0.2-\mu \mathrm{m}$ nitrocellulose membrane (Bio-Rad, 1620174). Blots were blocked in 5\% milk in TBST for $1 \mathrm{~h}$, and then incubated at $4^{\circ} \mathrm{C}$ overnight with one of the following antibodies: anti-gad65; anti-gad67; antiSST; anti-gapdh (Santa Cruz Biotechnology, sc377145, sc28376, sc7819, and sc32233, respectively), anti-CLB (Swant Marly, Cb38), and anti-CRT (Millipore Sigma, AB1550). Bands were detected with appropriate horseradish peroxide-conjugated secondary antibodies, reacted with chemiluminescent ECL substrate (Bio-Rad, 1705060) and visualized with a Bio-Rad ChemiDoc Imaging system. Band intensity was measured using the ImageJ program $(\mathrm{NIH})$.

\section{Behavioral experiments}

Testing began at P30 and a one-week intertest interval was provided between each test paradigm.

\section{Barnes maze investigation and reinvestigation}

The Barnes maze (Stoelting Co) consisted of a circular disk with equally spaced holes. The number and position of nose-pokes over a 10-min period were recorded for each animal. Repeated pokes into previously explored holes were divided by the number of initial pokes.

\section{Y-maze spontaneous alternation}

Mice were placed in a Y-shaped maze. The number of arm entries over a 10-min period was recorded. The alternation index was calculated as the number of total complete alternations, divided by the total number of arm entries minus two and expressed as a percentage.

\section{Water T-maze and reversal learning}

Testing occurred in a 6-cm-deep T-maze (Stoelting Co) filled with water $\left(22 \pm 1^{\circ} \mathrm{C}\right)$. A clear platform $10 \mathrm{~mm}$ under the water surface was placed at the end of the left or right arms. On days 1-5, animals were trained to locate the hidden platform with four trials per day. On day 6, the platform location was switched to the opposite arm of the T-maze and training continued until day 9.

\section{Socialization test}

Testing occurred in a three-chamber box (Stoelting Co). The two outer compartments contained metal wire cages where stranger mice 1 and 2 (S1 and S2) were held. After 10 min of habituation, the test animal was placed in the middle chamber with the adjacent doors closed. S1 was placed in one cage and an object $(\mathrm{O})$ in the other. The doors were opened to allow the test animal 10 min exploration. Social interaction duration (test mouse nose in contact with cage containing S1) was measured. S2 subsequently replaced the $\mathrm{O}$ and the test mouse was allowed another 10 min exploration. The time spent with either S1 or $\mathrm{S} 2$ was divided by the time spent with $\mathrm{S} 1+\mathrm{O}$ for social preference, or S1+S2 for novelty, and expressed as percentage. 


\section{Open field}

Anxiety and activity were examined in an open field $(40 \times$ $40 \mathrm{~cm}$; Stoelting). Mice were recorded and analyzed over 10 min with ANY-maze (Stoelting). Tracing paths of the mice were recorded and time spent in the central part $(25 \times 25$ $\mathrm{cm})$ versus time spent at the border was evaluated.

\section{Marble burying}

This test for repetitive behavior was performed in a box filled with $5 \mathrm{~cm}$ of bedding. Twelve glass marbles were evenly placed on the surface of the bedding. The number of buried marbles (to 2/3 of their depth) was counted after a 30-min exploration period.

\section{Statistics}

All experiments and analysis were performed blind to conditions. Statistical analysis was performed using PRISM software (GraphPad Software 6.0). Normal distribution of each dataset was analyzed by Shapiro-Wilk test. When two conditions were compared, data were analyzed with a nonparametric Mann-Whitney test. When four experimental groups were assessed, and three conditions compared to the control group, data were analyzed with a one-way ANOVA with Holm-Sidak's multiple comparisons or Kruskal-Wallis with Dunn's multiple comparisons. When four experimental groups were assessed and two variables were taken into consideration, data were analyzed with a two-way ANOVA with Fisher LSD, Sidak's or Tukey's multiple comparisons. In Figure 2, the statistical analysis was performed layer by layer with a Kruskal-Wallis with Dunn's multiple comparisons. The null hypothesis was rejected for $\alpha>5 \%$. The Statistical analysis is reported in detail in Table 2.

\section{Results}

\section{Major subtypes of interneurons are decreased in the human preterm PFC}

The PFC, including BA9, is one of the brain regions most frequently altered in psychiatric disease. To address whether interneuron density in this region was altered by prematurity, BA9 sections from 13 term and 14 preterm infants were obtained. Mean age of death (absolute age) was 1.5 months in term infants and 3.7 months for preterm infants delivered between 26 and 34 weeks of gestation (average corrected age 1.1 months). Sex, gestational weeks and cause of death varied, but none were attributed to CNS infection, hemorrhage or malformation (Table 1). Genetic diseases or anatomic birth defects were excluded.

Interneuron subtypes express specific molecular markers, in addition to expressing markers for GABA synthesis (GAD65 and GAD67). These subtypes have distinct morphologies, connectivity and physiology that allow precise inhibitory control of local neural networks (Tremblay et al., 2016). Some types can be identified by non-overlapping marker expression [SST, PV, and sets of vasoactive intestinal peptide (VIP) expressing and non-expressing interneurons] while other molecular markers are expressed in populations that overlap with the major markers [CRT, CLB, or neuropeptide Y (NPY)]. Major subclasses of interneurons were assessed by immunostaining for GAD6567, SST, CLB, CRT, and NPY to detect the major types of human interneurons for which antibodies are available [in male (Fig. 1) and female (Extended Data Fig. 1-1), term and preterm infants] not). Interneurons were counted in three sub-regions of BA9; the ULs, LLs, and the SWM.

A trend toward decrease was observed in the BA9 of human preterm male infants for GAD65-67 $7^{+}(\mathrm{UL}-24 \% \mathrm{~ns}$, $\mathrm{LL}-16 \%$ ns, SWM $+17 \%$, ns; Fig. $\left.1 A, A^{\prime}\right)$ and a significant reduction in the number of $\mathrm{SST}^{+}(\mathrm{UL}-31 \% p<0.05$, LL $-2 \%$ ns, SWM +1\%, ns; Fig. 1B, $\left.B^{\prime}\right)$ and CLB $^{+}(U L-28 \%$ $p<0.05$, LL $+15 \%$ ns, SWM +9\%, ns; Fig. 1C, $C^{\prime}$ ) interneurons in upper but not LLs. CRT ${ }^{+}$interneurons density was increased in the SWM (UL $-17 \%$ ns, LL $+9 \%$ ns, SWM +63\%, $p<0.05$; Fig. 1D, $\left.D^{\prime}\right)$. No change was observed in the number of $\mathrm{NPY}^{+}$interneurons (Fig. 1E, E'). $\mathrm{PV}^{+}$cells were not detected in this set of human samples, although these cells could be detected at later developmental stages (data not shown). No statistically significant change in total cortical layer widths was discernable based on Nissl staining (data not shown), suggesting overall preservation of pyramidal cells at this age. No difference was observed in female infants, but statistical power was limited by the small sample size (Extended Data Fig. 1-1). Global interneuron-related protein expression was not altered in the BA9 of preterm infants (Extended Data Fig. 1-2); however, interneuron-related transcripts for gad2 and calb1 were increased (Extended Data Fig. 1-3).

\section{The multi-hit model alters interneurons density and distribution}

To develop a new preclinical model that captures the multiple insults of human preterm brain injury, as well as the specific interneuron loss observed in the human samples studied here, prenatal MIA (induced by low dose LPS given late in gestation) was combined with postnatal CSH (induced by housing in a hypoxic environment for a week). Four experimental groups were used: mice whose dams were treated with saline and reared under normoxia (MIA-/CSH-); mice whose dams were treated with LPS and reared under normoxia (MIA+/CSH-); those treated with saline and reared in hypoxia (MIA-/CSH+); and those treated with LPS and reared in hypoxia (MIA+/CSH+; the "multi-hit" model).

Total interneuron density, illustrated in Figure $2 A-D$, was analyzed by counting cells positive for GAD65 and GAD67 in the two main sub-regions of the PFC, the ACC (Fig. $2 A^{\prime}, B^{\prime}$ ) and PL (Fig. $\left.2 A^{\prime \prime}, B^{\prime \prime}\right)$. Density and laminar distribution were analyzed and both GAD $65^{+}[-36 \% p<$ 0.05 (Fig. 2A'); $-33 \% p<0.05$ (Fig. 2A')] and GAD67 ${ }^{+}$ [-22\% $p<0.05$ (Fig. 2B'); $-23 \% p<0.05$ (Fig. 2B' ')] were significantly decreased in the MIA+/CSH+ cohort at P30. The multi-hit model also induced a long-lasting decrease in the density of SST ${ }^{+}\left[-32 \% p<0.05\right.$ (Fig. $2 C^{\prime}$ ); $-57 \% p$ $<0.05$ (Fig. 2C')] and CLB ${ }^{+}[-22 \% p<0.05$ (Fig. 2D'); $-57 \% p<0.05$ (Fig. 2D')], similar to the findings in human preterm PFC. In this animal model, no interneuron sex differences were detected so sexes were combined in further analyses.

Five additional subtypes of interneuron present in the PFC of mice were analyzed: PV (Extended Data Fig. 2-1A), VIP (Extended Data Fig. 2-1B), CRT (Extended Data 
Table 2. Statistical analysis

\begin{tabular}{l}
\hline Dataset \\
Fig. $1 A$ \\
Fig. $1 B$ \\
Fig. $1 C$ \\
Fig. $1 D$ \\
Fig. $1 E$ \\
Extended Data Fig. 1-1A \\
Extended Data Fig. 1-1B \\
Extended Data Fig. 1-1C \\
Extended Data Fig. 1-1D \\
Extended Data Fig. 1-1E \\
Extended Data Fig. 1-2B \\
Extended Data Fig. 1-2C \\
Extended Data Fig. 1-2D \\
Extended Data Fig. 1-2E \\
Extended Data Fig. 1-2F \\
Extended Data Fig. 1-3A \\
Extended Data Fig. 1-3B \\
Extended Data Fig. 1-3C \\
Extended Data Fig. 1-3D \\
Extended Data Fig. 1-3E \\
Extended Data Fig. 1-3F
\end{tabular}

Fig. $2 A$

Fig. $2 B$

Fig. $2 C$

Fig. $2 D$

Extended Data Fig. 2-1A

Extended Data Fig. 2-1B

Extended Data Fig. 2-1C

Extended Data Fig. 2-1D

Extended Data Fig. 2-1D

Fig. $3 A$

Fig. $3 B$

Fig. $3 C$

Extended Data Fig. 3-1A Extended Data Fig. 3-1B Extended Data Fig. 3-1C

Extended Data Fig. 3-2 Extended Data Fig. 3-3B Extended Data Fig. 3-3C

Fig. $4 A$

Fig. $4 B$
Data structure

Non-normal distribution Non-normal distribution Non-normal distribution Non-normal distribution Non-normal distribution Non-normal distribution Non-normal distribution Non-normal distribution Non-normal distribution Non-normal distribution Non-normal distribution Non-normal distribution Non-normal distribution Non-normal distribution Non-normal distribution Non-normal distribution Non-normal distribution Non-normal distribution Non-normal distribution Non-normal distribution Non-normal distribution

Non-normal distribution

Non-normal distribution

Non-normal distribution

Non-normal distribution

Non-normal distribution

Non-normal distribution

Non-normal distribution

Non-normal distribution

Non-normal distribution

Non-normal distribution Non-normal distribution

Non-normal distribution

Non-normal distribution Non-normal distribution Non-normal distribution

Non-normal distribution Non-normal distribution Non-normal distribution

Non-normal distribution Non-normal distribution
Type of test

Two-way ANOVA, uncorrected Fisher's LSD Two-way ANOVA, uncorrected Fisher's LSD Two-way ANOVA, uncorrected Fisher's LSD Two-way ANOVA, uncorrected Fisher's LSD Two-way ANOVA, uncorrected Fisher's LSD Two-way ANOVA, uncorrected Fisher's LSD Two-way ANOVA, uncorrected Fisher's LSD Two-way ANOVA, uncorrected Fisher's LSD Two-way ANOVA, uncorrected Fisher's LSD Two-way ANOVA, uncorrected Fisher's LSD Two-way ANOVA, Sidak's multiple comparisons Two-way ANOVA, Sidak's multiple comparisons Two-way ANOVA, Sidak's multiple comparisons Two-way ANOVA, Sidak's multiple comparisons Two-way ANOVA, Sidak's multiple comparisons Two-way ANOVA, Sidak's multiple comparisons Two-way ANOVA, Sidak's multiple comparisons Two-way ANOVA, Sidak's multiple comparisons Two-way ANOVA, Sidak's multiple comparisons Two-way ANOVA, Sidak's multiple comparisons Two-way ANOVA, Sidak's multiple comparisons

Kruskal-Wallis, Dunn's multiple comparisons

Kruskal-Wallis, Dunn's multiple comparisons

Kruskal-Wallis, Dunn's multiple comparisons

Kruskal-Wallis, Dunn's multiple comparisons

Kruskal-Wallis, Dunn's multiple comparisons

Kruskal-Wallis, Dunn's multiple comparisons

Kruskal-Wallis, Dunn's multiple comparisons

Kruskal-Wallis, Dunn's multiple comparisons

Kruskal-Wallis, Dunn's multiple comparisons

Two-way ANOVA, Sidak's multiple comparisons Mann-Whitney

Mann-Whitney

Mann-Whitney

Mann-Whitney

Two-way ANOVA, Sidak's multiple comparisons

Mann-Whitney

Mann-Whitney

Mann-Whitney

Kruskal-Wallis, Dunn's multiple comparisons Kruskal-Wallis, Dunn's multiple comparisons
Power

UL: $p=0.1337, \mathrm{LL}: p=0.4334$, SWM: $p=0.5985$

UL: $p=0.0425$, LL: $p=0.9257$, SWM: $p=0.9609$

UL: $p=0.0278$, LL: $p=0.4931$, SWM: $p=0.7801$

UL: $p=0.2880$, LL: $p=0.6393$, SWM: $p=0.0240$

UL: $p=0.9257$, LL: $p=0.9397$, SWM: $p=0.2848$

UL: $p=0.9265$, LL: $p=0.5300$, SWM: $p=0.4023$

UL: $p=0.8052$, LL: $p=0.3294$, SWM: $p=0.8217$

UL: $p=0.3699$, LL: $p=0.9644$, SWM: $p=0.9559$

UL: $p=0.3370$,LL: $p=0.2271$, SWM: $p=0.3900$

UL: $p=0.7681$, LL: $p=0.7659$, SWM: $p=0.6875$

Male: $p=0.9428$, female: $p=0.7868$

Male: $p=0.3033$, female: $p=0.8720$

Male: $p=0.9960$, female: $p=0.7304$

Male: $p=0.9940$, female: $p=0.9212$

Male: $p=0.8677$, female: $p=0.8035$

Male: $p=0.6754$, female: $p=0.9993$

Male: $p=0.0497$, female: $p=0.4501$

Male: $p=0.7528$, female: $p=0.6561$

Male: $p=0.0412$, female: $p=0.9986$

Male: $p=0.8936$, female: $p=0.9142$

Male: $p=0.9886$, female: $p=0.3146$

ACC: Layer I: MIA+/CSH $-p<0.05$, Layer II/III

$\mathrm{MIA}+/ \mathrm{CSH}+p<0.05$, PL: Layer I: MIA $+/ \mathrm{CSH}-$

$p<0.05$, Layer II/III MIA $+/ \mathrm{CSH}+p<0.05$

ACC: Layer II/III: MIA $+/ C S H-p<0.05$,

$\mathrm{MIA}-/ \mathrm{CSH}+p<0.05, \mathrm{MIA}+/ \mathrm{CSH}+p<0.05$,

$\mathrm{PL}:$ Layer II/III: $\mathrm{MIA}+/ \mathrm{CSH}+p<0.05$

ACC: Layer I: $\mathrm{MIA}+/ \mathrm{CSH}-p<0.05, \mathrm{MIA}+/ \mathrm{CSH}+$

$p<0.05$, Layer II/III: MIA $+/ \mathrm{CSH}+p<0.05$,

Layer V: $\mathrm{MIA}+/ \mathrm{CSH}+p<0.05$, PL: Layer I:

$\mathrm{MIA}+/ \mathrm{CSH}+p<0.05$, Layer II/III: MIA $+/ \mathrm{CSH}+$

$p<0.05$, Layer V: $\mathrm{MIA}+/ \mathrm{CSH}-p<0.05$

ACC: Layer I: MIA $+/ \mathrm{CSH}+p<0.05$, Layer II/III:

$\mathrm{MIA}+/ \mathrm{CSH}+p<0.05$, PL: Layer I: MIA $+/ \mathrm{CSH}-$

$p<0.05, \mathrm{MIA}+/ \mathrm{CSH}+p<0.05$, Layer II/III:

$\mathrm{MIA}+/ \mathrm{CSH}-p<0.05, \mathrm{MIA}+/ \mathrm{CSH}+p<0.05$,

$\mathrm{MIA}+/ \mathrm{CSH}+p<0.05$

ACC: Layer II/III: MIA $+/ C S H+p<0.05$, PL: Layer II/III $\mathrm{MIA}+/ \mathrm{CSH}+p<0.05$

ACC: Layer $V \mathrm{MIA}+/ \mathrm{CSH}-p<0.05, \mathrm{MIA}+/ \mathrm{CSH}+$ $p<0.05$, PL: Layer II/III: MIA $+/ \mathrm{CSH}-p<0.05$, $\mathrm{MIA}+/ \mathrm{CSH}+p<0.05$, Layer $\mathrm{V}: \mathrm{MIA}+/ \mathrm{CSH}+p$ $<0.05$

ACC: Layer V MIA-/CSH $+p<0.05, \mathrm{MIA}+/ \mathrm{CSH}+$ $p<0.05$, PL: Layer V MIA-/CSH $+p<0.05$, $\mathrm{MIA}+/ \mathrm{CSH}+$, Layer V I: MIA-/CSH $+p<0.05$

ACC: Layer V and Layer VI: MIA $+/ \mathrm{CSH}-p<0.05$, $\mathrm{MIA}-/ \mathrm{CSH}+p<0.05, \mathrm{MIA}+/ \mathrm{CSH}+p<0.05$, PL: Layer II/III: MIA $+/ \mathrm{CSH}-p<0.05$, $\mathrm{MIA}-/ \mathrm{CSH}+p<0.05, \mathrm{MIA}+/ \mathrm{CSH}+p<0.05$, Layer V: $\mathrm{MIA}+/ \mathrm{CSH}+p<0.05$

ACC: Layer I: MIA-/CSH $+p<0.05$, PL: ns

$\mathrm{MZ}: p<0.05, \mathrm{CP}: p \leq 0.05$, SVZNZ $p<0.05$

$\operatorname{gad} 65+: p=0.3333, \mathrm{ki} 67+: p=0.0381, \operatorname{gad} 65+/$ $\mathrm{ki} 67+: p=0.0095$

$\operatorname{gad} 65+: p=0.0012$, brdu $+: p<0.001, \operatorname{gad} 65+1$ brdu+: $p=0.0012$

ns

ns

$\mathrm{MZ}: p=0.714, \mathrm{CP}: p=0.04521, \mathrm{SVZ} / \mathrm{VZ}: p=$ 0.1657

$p=0.0688$

$p=0.0047$

$p=0.0315$

gad65+: $\mathrm{MIA}+/ \mathrm{CSH}+p<0.05$

gad65+: $\mathrm{MIA}+/ \mathrm{CSH}+p<0.05$; gad65+/brdu+:

$\mathrm{MIA}+/ \mathrm{CSH}+p<0.05$ 
Table 2. Continued

\begin{tabular}{|c|c|c|c|}
\hline Dataset & Data structure & Type of test & Power \\
\hline Fig. 5 & Non-normal distribution & $\begin{array}{l}\text { Two-way ANOVA, Tukey's multiple } \\
\text { comparisons }\end{array}$ & $\begin{array}{l}\text { e17.5: } \mathrm{MIA}+/ \mathrm{CSH}-p<0.001, \mathrm{P} 10: \mathrm{MIA}+/ \mathrm{CSH}+p \\
\quad<0.05, \mathrm{P} 30: \mathrm{MIA}+/ \mathrm{CSH}+p<0.05\end{array}$ \\
\hline Fig. $6 A$ & Non-normal distribution & Mann-Whitney & iba1 $+: p=0.0067$, cd68+: $p=0.0163$ \\
\hline Fig. $6 B$ & Non-normal distribution & Kruskal-Wallis, Dunn's multiple comparisons & iba1+: ns, cd68+: MIA $+/ C S H+p<0.01$ \\
\hline Fig. $6 C$ & Non-normal distribution & Kruskal-Wallis, Dunn's multiple comparisons & iba1+: ns, cd68+: ns \\
\hline Fig. $7 A$ & Normal distribution & $\begin{array}{l}\text { One-way ANOVA, Holm-Sidak's multiple } \\
\text { comparisons }\end{array}$ & $\mathrm{MIA}+/ \mathrm{CSH}-p<0.05, \mathrm{MIA}+/ \mathrm{CSH}+p<0.001$ \\
\hline Fig. $7 B$ & Normal distribution & $\begin{array}{l}\text { One-way ANOVA, Holm-Sidak's multiple } \\
\text { comparisons }\end{array}$ & $\mathrm{MIA}+/ \mathrm{CSH}+p<0.01$ \\
\hline Fig. $7 C$ & Normal distribution & $\begin{array}{l}\text { Two-way ANOVA, Tukey's multiple } \\
\text { comparisons }\end{array}$ & ns \\
\hline Fig. $7 D$ & Normal distribution & $\begin{array}{l}\text { Two-way ANOVA, Tukey's multiple } \\
\text { comparisons }\end{array}$ & $\begin{array}{l}\mathrm{d} 2: \mathrm{MIA}+/ \mathrm{CSH}+p<0.05, \mathrm{~d} 3: \mathrm{MIA}+/ \mathrm{CSH}+p< \\
\quad 0.05\end{array}$ \\
\hline Fig. $7 E$ & Normal distribution & $\begin{array}{l}\text { One-way ANOVA, Holm-Sidak's multiple } \\
\text { comparisons }\end{array}$ & ns \\
\hline Fig. $7 F$ & Normal distribution & $\begin{array}{l}\text { One-way ANOVA, Holm-Sidak's multiple } \\
\text { comparisons }\end{array}$ & $\mathrm{MIA}+/ \mathrm{CSH}+p<0.05$ \\
\hline Fig. $7 G$ & Normal distribution & $\begin{array}{l}\text { One-way ANOVA, Holm-Sidak's multiple } \\
\text { comparisons }\end{array}$ & $\mathrm{MIA}+/ \mathrm{CSH}-p<0.05, \mathrm{MIA}+/ \mathrm{CSH}+p<0.05$ \\
\hline Extended Data Fig. 7-1 $\mathrm{A}$ & Normal distribution & $\begin{array}{l}\text { One-way ANOVA, Holm-Sidak's multiple } \\
\text { comparisons }\end{array}$ & ns \\
\hline Extended Data Fig. 7-1B & Normal distribution & $\begin{array}{l}\text { One-way ANOVA, Holm-Sidak's multiple } \\
\text { comparisons }\end{array}$ & ns \\
\hline Extended Data Fig. 7-1C & Normal distribution & $\begin{array}{l}\text { One-way ANOVA, Holm-Sidak's multiple } \\
\text { comparisons }\end{array}$ & ns \\
\hline Extended Data Fig. 7-1D & Normal distribution & $\begin{array}{l}\text { One-way ANOVA, Holm-Sidak's multiple } \\
\text { comparisons }\end{array}$ & ns \\
\hline Extended Data Fig. 7-1E & Non-normal distribution & Kruskal-Wallis, Dunn's multiple comparisons & ns \\
\hline Extended Data Fig. 7-1F & Normal distribution & $\begin{array}{l}\text { One-way ANOVA, Holm-Sidak's multiple } \\
\text { comparisons }\end{array}$ & ns \\
\hline
\end{tabular}

$\mathrm{CP}$, cortical plate; MIA-/CSH-, mice treated with saline and reared under normoxia; MIA+/CSH-; mice subjected to MIA and reared under normoxia; MIA-/ $\mathrm{CSH}+$, mice treated with saline and reared under $\mathrm{CSH}$; $(\mathrm{MIA}+/ \mathrm{CSH}+)$, mice subjected to $\mathrm{MIA}$ and reared under $\mathrm{CSH}$; $\mathrm{MZ}$, marginal zone; ns, non-significant; SVZ/VZ, subventricular/ventricular zone.

Fig. 2-1C), NPY (Extended Data Fig. 2-1D), and RLN (Extended Data Fig. 2-1E). All subtypes except RLN were reduced. Only $\mathrm{PV}^{+}[-32 \% p<0.05$ (Extended Data Fig. $\left.2-1 A^{\prime}\right) ;-60 \% p<0.05$ (Extended Data Fig. 2-1 $\left.\left.A^{\prime \prime}\right)\right]$ and $\mathrm{SST}^{+}$(Fig. 2C-C'), both in Layer II/III, were exclusively decreased after both hits. Similarly, MIA altered the density and distribution of $\mathrm{VIP}^{+}$, in ACC Layer V (MIA+/CSH$-70 \% p<0.05$; MIA $+/ \mathrm{CSH}+-31 \% p<0.05$; Extended Data Fig. 2-1B') and PL Layer II/III (MIA+/CSH- $-43 \% p$ $<0.05, \mathrm{MIA}+/ \mathrm{CSH}+-41 \% p<0.05$; Extended Data Fig. $\left.2-1 B^{\prime \prime}\right)$. CSH alone led to a reduction in $\mathrm{CLB}^{+}$in Layer $\mathrm{V}$ that was similar to the multi-hit model [MIA-/CSH+ $-42 \%$ $p<0.05$, MIA $+/ \mathrm{CSH}+-22 \% p<0.05$ (Fig. 2D'); MIA-/ $\mathrm{CSH}+-38 \% p<0.05$, MIA $+/ \mathrm{CSH}+-57 \% p<0.05$ (Fig. $\left.2 D^{\prime \prime}\right)$ ]. In contrast $\mathrm{CRT}^{+}$and $\mathrm{NPY}^{+}$subtypes were decreased after either MIA or CSH, as well as by the combination of insults (Extended Data Fig. 2-1C,D). Taken together, these data point out unique changes induced in the multi-hit model in GAD65, GAD67, PV, and SST expressing interneurons.

\section{PFC interneuron loss due to MIA-induced alteration of proliferation and migration plus $\mathrm{CSH}$-induced maturation delay}

To understand the mechanisms underlying the alterations induced by the multi-hit model in the PFC, the direct effect of mild late inflammation was examined at E17.5. Comparing fetuses from MIA versus saline exposed gestations revealed a significant decrease in the number of
GAD65-GFP $^{+}$in three major sub-divisions of the developing cerebral cortex (MZ -36\%, CP $-33 \%$, SVZ/VZ $-25 \% p<0.05$; Fig. $\left.3 A-A^{\prime \prime}\right)$. To elucidate the cause of interneuron loss, Ki67 (a marker of mitosis) was used in combination with GAD65 to label interneuron progenitors proliferation in the caudal ganglionic eminence (CGE), one of the three germinative areas where the majority of $\mathrm{GAD}^{+} 5^{+}$interneurons are generated. At E17.5, MIA significantly reduced $\mathrm{Ki} 67^{+}$, and cells double-labeled for GAD $65^{+}$and Ki67 ${ }^{+}[-32 \% p<0.05$ (Fig. 3B') $-43 \% p<$ 0.01 (Fig. 3B*)]. Interneuron density in the medial ganglionic eminence (MGE) and preoptic area was determined by Nkx2.1 expression, a marker of interneuron progenitors. Like GAD65 ${ }^{+}, \mathrm{Nkx} 2.1^{+}$cell density did not differ in these germinative zones but was significantly decreased in embryonic cortex $(-35 \% p<0.05$; Extended Data Fig. 3-1).

To assess the contribution of survival and migration to the loss of cortical interneurons, MIA and saline control dams were injected at E15.5 with BrdU, which labels actively dividing cells during a restricted period (Fig. $3 C$ ). At E17.5, MIA exposure significantly decreased $\mathrm{BrdU}^{+}$ GAD65 ${ }^{+}$double-labeled cells in the PFC $(-72 \% p<0.01$; Fig. $3 C *)$. The contribution of apoptotic cell death to the loss of cortical interneurons was examined, but no significant difference was observed in cleaved caspase 3-positive cells (Extended Data Fig. 3-2). A small decrease in neuronal density was observed using $\mathrm{NeuN}^{+}(\mathrm{Ex}-$ 

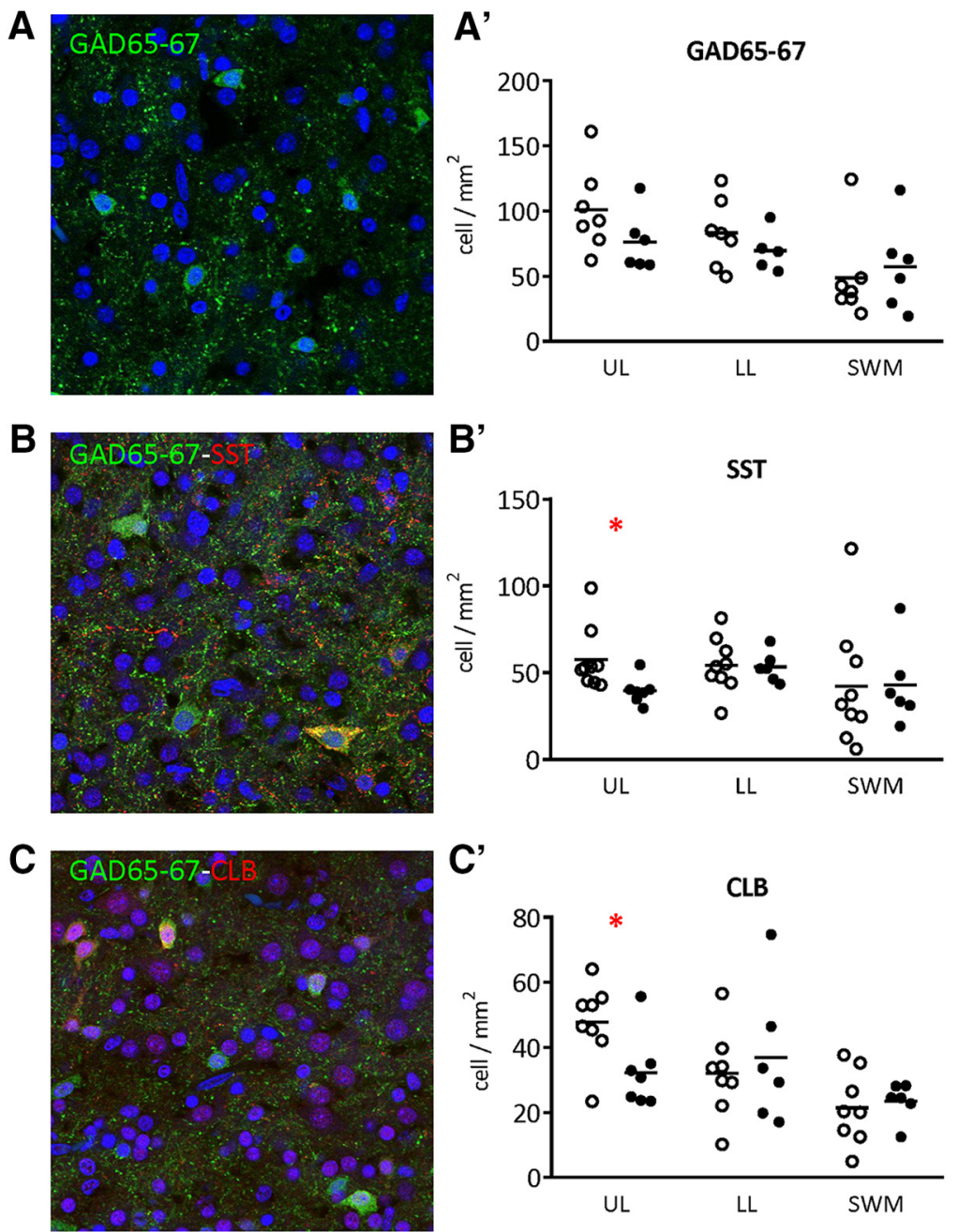

C'
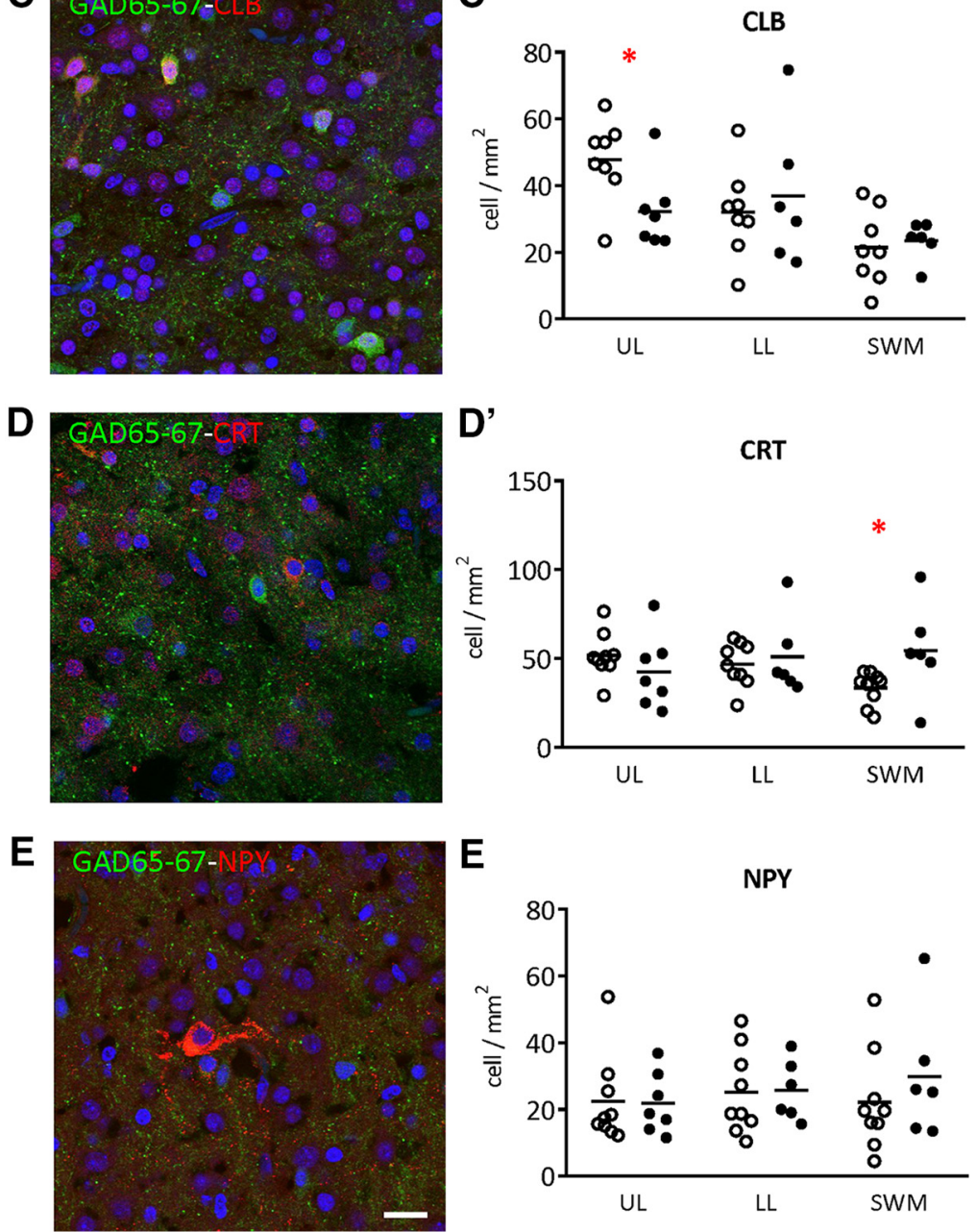

Figure 1. Effect of prematurity on interneurons density in BA9 of male infants. Illustrations of (A) glutamate decarboxylase 65 and 67 (GAD65-67, green), (B) SST (red), (C) CLB (red), (D) CRT (red), and (E) NPY (red) interneurons density. Scale bar $=20 \mu \mathrm{m}$. 
continued

Quantification of $\left(\boldsymbol{A}^{\prime}\right)$ GAD65-67, $\left(\boldsymbol{B}^{\prime}\right)$ SST, $\left(\boldsymbol{C}^{\prime}\right)$ CLB, $\left(\boldsymbol{D}^{\prime}\right)$ CRT, and $\left(\boldsymbol{E}^{\prime}\right)$ NPY positive cells in the upper layers (ULs), lower layers (LLs) and subcortical white matter (SWM) of the BA9 of the frontal cortex of term and preterm male infants. BA9 of female infants are presented on Extended Data Figure 1-1. Interneuron-related protein expression and transcripts are presented in Extended Data Figures 1-2, 1-3, respectively. Scatter dot plots represent the mean and individual dispersion of seven to nine term (empty circles) and six to seven preterm infants (full circles); $* p<0.05$ (two-way ANOVAs were performed followed by Fisher's LSD tests for post hoc comparisons).

A
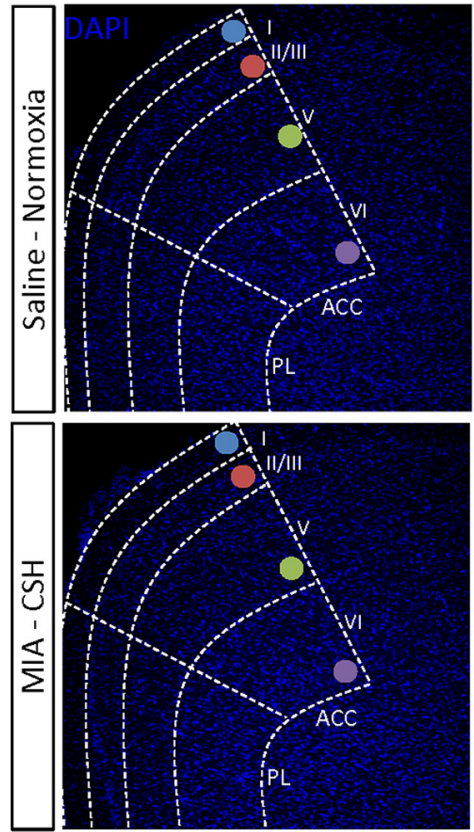

A'

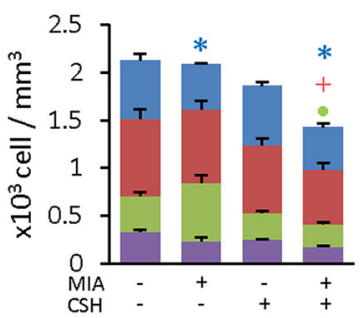

A"

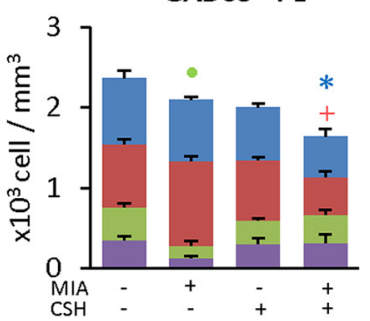

B
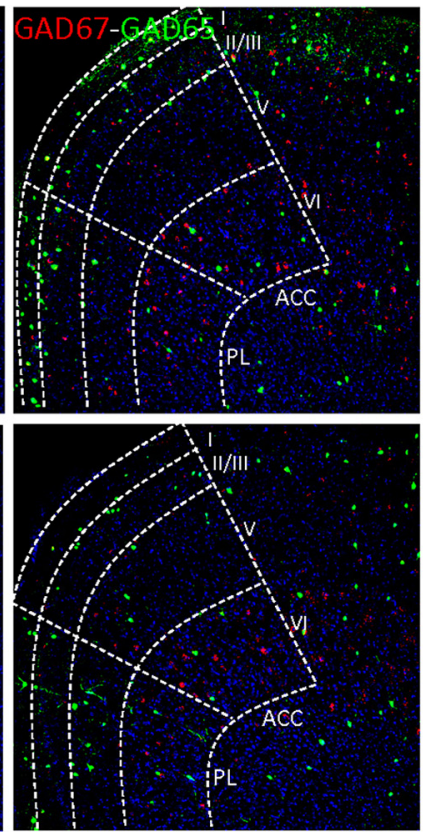

B'

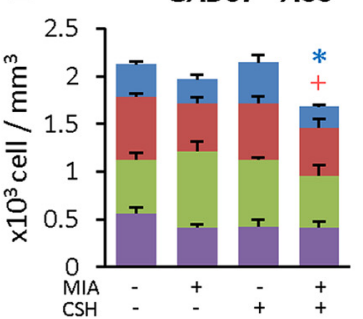

B"

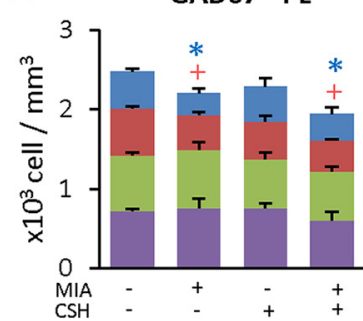

C
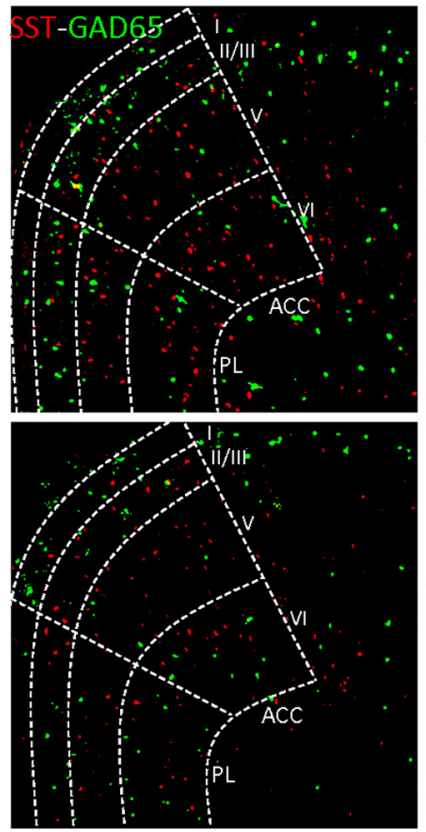

C'

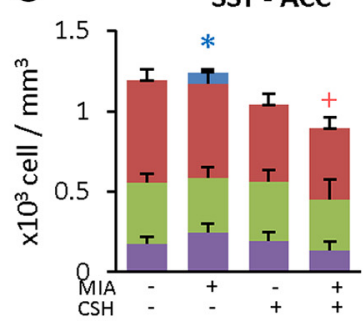

C"

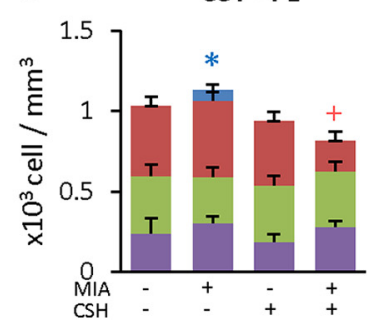

D
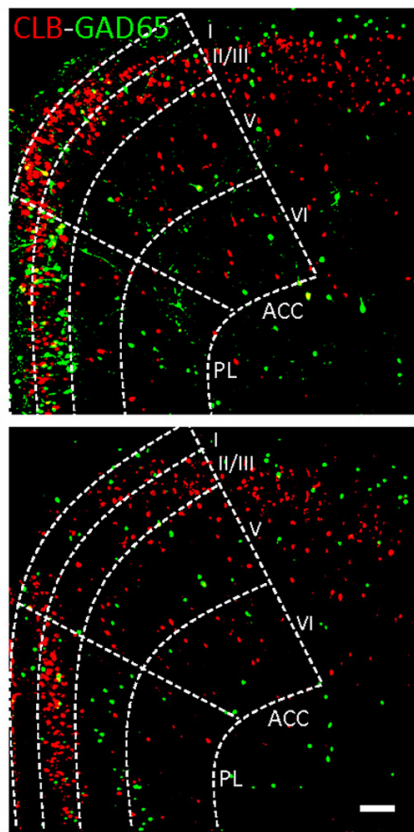

D'

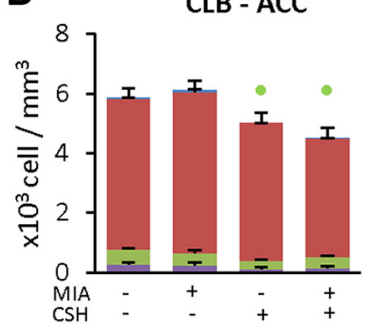

D"

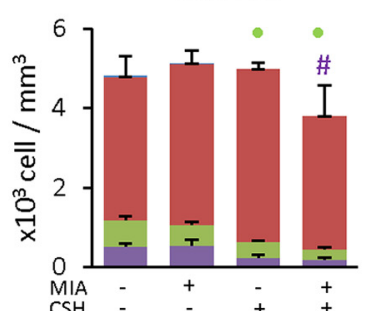

Figure 2. Effect of the multi-hit model on interneuron abundance and distribution in the anterior cingulate cortex (ACC) and prelimbic area $(\mathrm{PL})$ of the PFC at P30. Illustration of $(\boldsymbol{A})$ cortical layer delineation with DAPI (blue), the density and laminar distribution of GAD65 (green) overlaid with (B) GAD67, (C) SST, and (D) CLB (red) in the ACC and PL Layers I, II/III, V, and VI of mice treated with saline and reared under normoxia or subjected to MIA (injected with $150 \mu \mathrm{g} / \mathrm{kg}$ of LPS at E15.5 and E16.5) and reared under CSH. Scale bar $=$ $100 \mu \mathrm{m}$. Five additional subtypes of interneuron were analyzed and are presented in Extended Data Figure 2-1. Quantification of interneurons $\left(\boldsymbol{A}^{\prime}-\boldsymbol{D}^{\prime}\right)$ in the ACC and $\left(\boldsymbol{A}^{\prime \prime}-\boldsymbol{D}^{\prime \prime}\right)$ in the PL of mice treated with saline and reared under normoxia, subjected to with MIA and reared under normoxia, treated with saline and reared under CSH and subjected to MIA and reared under CSH. Layers densities are stacked and blue, red, green, and purple colors are assigned for Layers I, II/III, V, and VI, respectively. Values represent the mean ( \pm SEM) from five to six animals out two pregnancies. $*,+, \bullet, \# p<0.05$ (Kruskal-Wallis with Dunn's comparisons). 
A

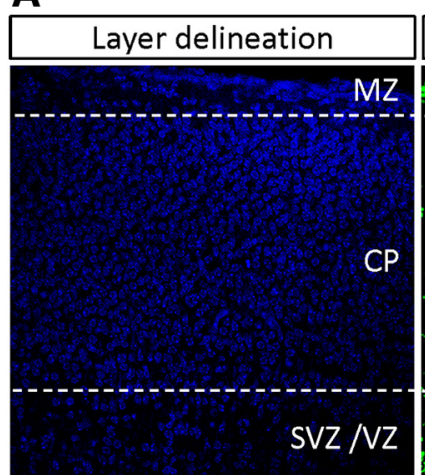

B

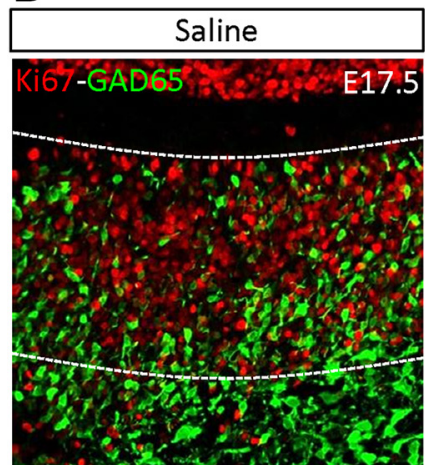

B'

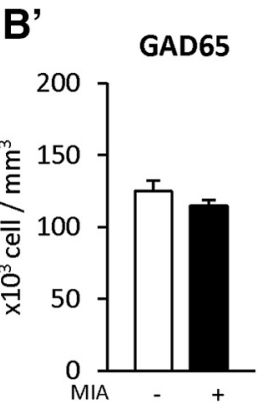

$A^{\prime}$
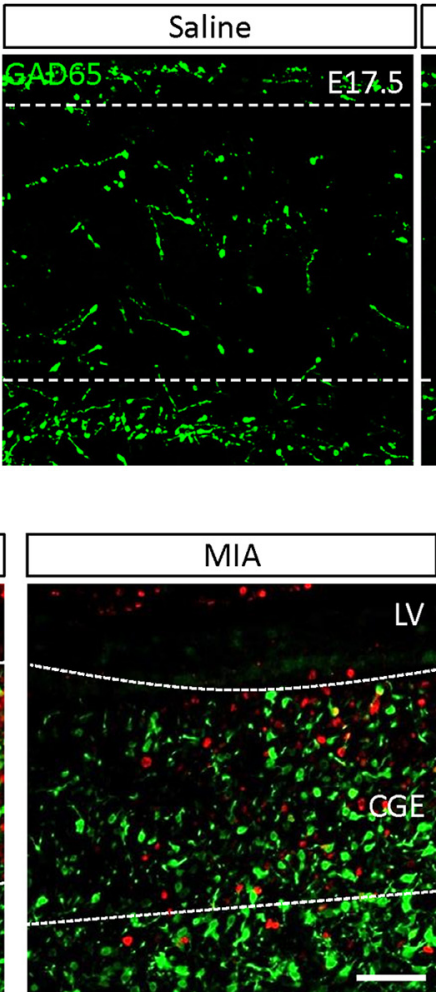

B"
$\mathbf{B}^{*}$

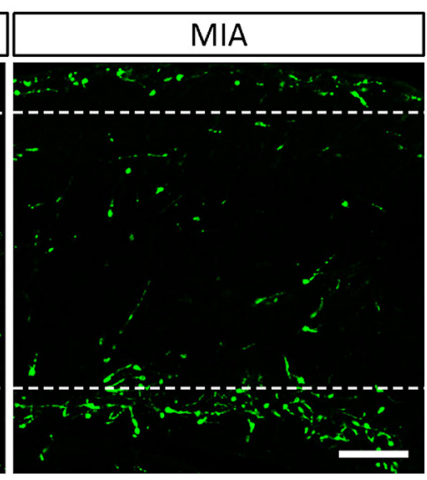

C

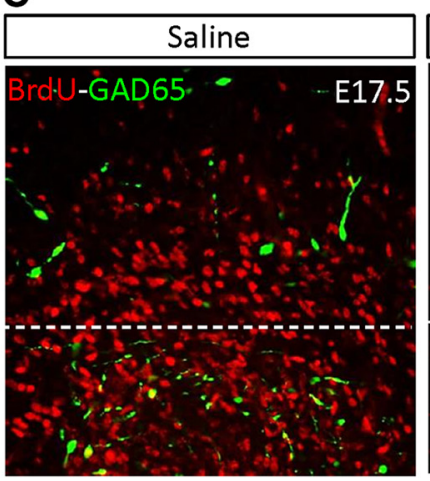

C'
A"

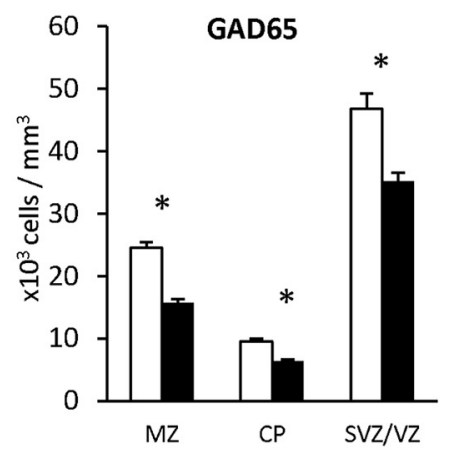

Figure 3. Effect of MIA at E17.5 on interneuron progenitor's proliferation and fate. $\boldsymbol{A}$, Delineation of the sub-regions of the embryonic cortex with DAPI (blue). $\boldsymbol{A}^{\prime}$, GAD65 density at E17.5 in the marginal zone (MZ), cortical plate (CP), and subventricular/ventricular zone (SVZ/VZ; green). Scale bar $=100 \mu \mathrm{m}$. A', Quantification of GAD65 positive cells in the MZ, CP, SVZ/VZ. B, GAD65 proliferation at E17.5 in the remaining CGE [density of GAD65 (green) and Ki67 (red)]. Scale bar $=50 \mu \mathrm{m}$. Proliferation in the other ganglionic eminence areas is presented in Extended Data Figure 3-1. Quantification of (B') GAD65, (B') $\mathrm{Ki67}$, and $(\boldsymbol{B} *)$ GAD65 and Ki67 co-labeled cells density in the CGE; (C) GAD65 cell fate in the cerebral cortex at E17.5 [GAD65 (green) and BrdU (red)] in mice subjected to saline or MIA (injected with $150 \mu \mathrm{g} / \mathrm{kg}$ of LPS at E15.5 and E16.5). Scale bar $=50 \mu \mathrm{m}$. Quantification of $\left(\boldsymbol{C}^{\prime}\right)$ GAD65, $\left(\boldsymbol{C}^{\prime \prime}\right)$ BrdU, and $(\boldsymbol{C} *)$ GAD65 and BrdU positive cells in the cerebral cortex of mice treated with saline (white bars) and subjected to MIA (black bars). Apoptotic cell death and total neuronal densities are presented in Extended Data Figures 3-2, 3-3, respectively. Values represent the mean ( \pm SEM) from five to six animals out two pregnancies. $\boldsymbol{A}^{\prime}, * p<0.05$ (two-way ANOVA with Sidak's multiple comparisons); $\boldsymbol{B}, \boldsymbol{C}, * p<0.5, * * p<0.01$, ***p $<001$ (Mann-Whitney).

tended Data Fig. 3-3), but this reduction was significantly less than the percentage of $\mathrm{GAD} 65^{+}$neurons lost. Overall, these data highlight alterations of interneuron proliferation and suggest an alteration of migration induced by MIA.

To examine the molecular factors involved in interneuron loss, the expression of 18 interneuron-related transcripts was assessed at E17.5 in the cerebral cortex of mice subjected to MIA or saline. A significant increase was observed in the expression of fate determination (gad2, +57\%; nkx2.1, +142\%; Ihx6, +92\%; ki67, +62\%; Table 3) and migration mRNAs (dlx1, +51\%; dlx5, $+176 \%$; Table 3) suggesting that early interneuron suppression may lead to a compensatory increases in genes that can promote subsequent interneuron progenitor production.

The addition of postnatal hypoxia was then assessed (Fig. 4). In $\mathrm{MIA}+/ \mathrm{CSH}-$ mice, $\mathrm{GAD}^{+} 5^{+}$cell numbers recovered by $\mathrm{P} 10$. This recovery was abolished by addition of $\mathrm{CSH}(\mathrm{MIA}+/ \mathrm{CSH}--8 \% \mathrm{~ns}, \mathrm{MIA}+/ \mathrm{CSH}+-49 \% p<$ 
Table 3. Effect of MIA at E17.5 on the regulation of interneurons fate determination and migration-related transcripts

\begin{tabular}{|c|c|c|c|c|}
\hline Gene symbol & Gene name & Fold change & SEM & Significance \\
\hline gad1 (gad67) & Glutamate decarboxylase 1 & 1.11 & 0.07 & \\
\hline gad2 (gad65) & Glutamate decarboxylase 2 & 1.57 & 0.07 & $*$ \\
\hline $\mathrm{nkx} 2.1$ & NK2 homeobox 1 & 2.42 & 0.29 & $* * *$ \\
\hline ascl1 (mash1) & Achaete-scute family bHLH transcription factor 1 & 1.39 & 0.09 & \\
\hline pax6 & Paired box 6 & 1.02 & 0.16 & \\
\hline lhx6 & LIM homeobox protein 6 & 1.92 & 0.19 & * \\
\hline ki67 & Antigen identified by monoclonal antibody Ki67 & 1.62 & 0.08 & * \\
\hline dlx1 & Distal-less homeobox 1 & 1.51 & 0.07 & * \\
\hline dlx2 & Distal-less homeobox 2 & 1.12 & 0.17 & \\
\hline dlx5 & Distal-less homeobox 5 & 2.76 & 0.53 & $* * *$ \\
\hline dlx6 & Distal-less homeobox 6 & 0.98 & 0.10 & \\
\hline
\end{tabular}

Quantification of mRNA levels in E17.5 embryos. Each value represents the mean $( \pm \mathrm{SEM})$ from at least five embryos out of at least two pregnancies; $* p<$ $0.05 ; * * * p<0.001$ (Mann-Whitney).

0.05; Fig. 4A'). With hypoxia treatment alone (MIA-/ $\mathrm{CSH}+$ ), fewer GAD65 ${ }^{+}$cells were also seen, suggesting a direct effect of hypoxia on interneuron survival which was confirmed by co-labeling GAD65 with BrdU (injected at E15.5; Fig. 4A" '). MIA+/CSH+ cortex at P30 showed long-lasting interneuron deficits (Fig. 4B- $B$ "). Overall, MIA induced an early loss of interneurons through proliferation and migration defects which, with the addition of $\mathrm{CSH}$, prevented recovery so that these deficits persisted into adulthood (MIA+/CSH+ E17.5\% $-44 \% p<0.001, \mathrm{P} 10-49 \% p<0.05, \mathrm{P} 30-37 \% p<$ 0.05; Fig. 5).

\section{The addition of CSH induced a second burst of inflammation}

To determine the effect of the multi-hit model on inflammation, the density of lba1 positive cells was used to determine the total number of microglia and $\mathrm{Iba} 1^{+} \mathrm{CD}^{+} 8^{+}$ double-labeled cells detected microglial activation. At E17.5, microglial numbers $\left(+22 \% p<0.05\right.$; Fig. $\left.6 A^{\prime}\right)$ and microglial activation $\left(+75 \% p<0.01\right.$; Fig. $\left.6 A^{\prime \prime}\right)$ were increased by MIA. By P10, only MIA+/CSH+ significantly increased activated microglia (MIA+/CSH- +61\%, ns; $\mathrm{MIA}-/ \mathrm{CSH}++34 \%$, ns; $\mathrm{MIA}+/ \mathrm{CSH}++135 \%, p<0.01$; Fig. $\left.6 B^{\prime \prime}\right)$, suggesting a sensitization of microglial cells by
A
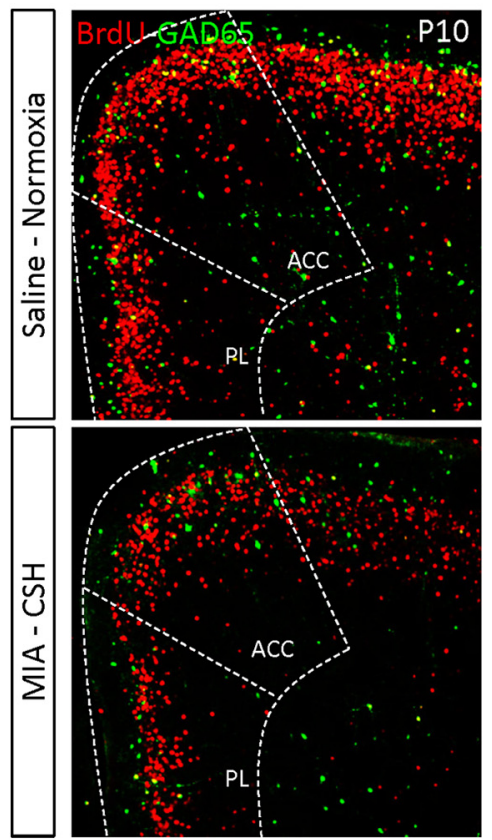

A'

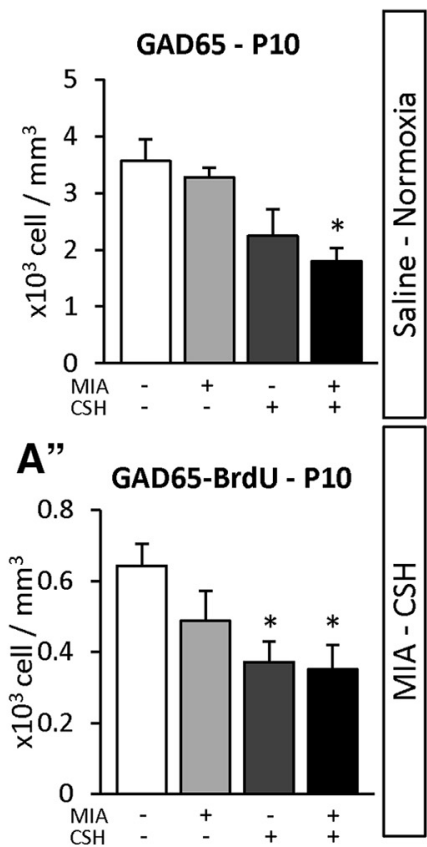

B
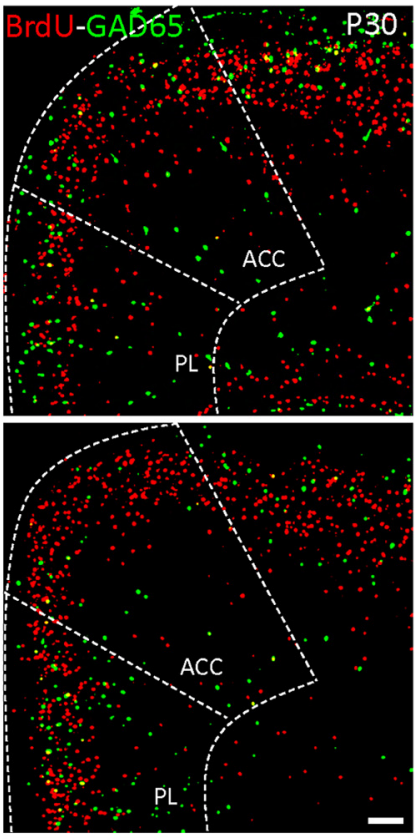

B'
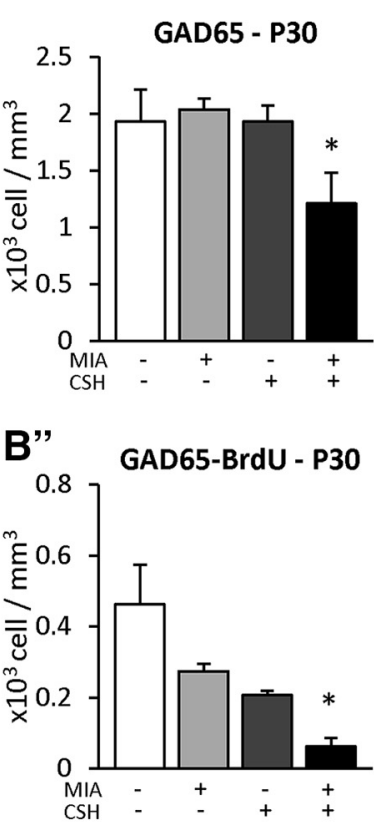

Figure 4. Effect of the multi-hit model on interneuron density and fate in the PFC at $(\boldsymbol{A}) \mathrm{P} 10$ and $(\boldsymbol{B}) \mathrm{P} 30$. GAD65 cell fate in the PFC [GAD65 (green) and BrdU (red)] of $(\boldsymbol{A})$ mice treated with saline and reared under normoxia or subjected MIA and reared under CSH. Scale bar $=100 \mu \mathrm{m}$. Quantification of $\left(\boldsymbol{A}^{\prime}\right)$ GAD65, (B') GAD65 and BrdU co-labeled cell density of P10; and (A') GAD65, (B') GAD65 and BrdU co-labeled cell density at P30 in the PFC (ACC and PL are added for reference) treated with saline and reared under normoxia, subjected to with MIA and reared under normoxia, treated with saline and reared under CSH, subjected to MIA and reared under CSH. Values represent the mean ( \pm SEM) from five to six animals out two pregnancies; $* p<0.05$ (Kruskal-Wallis test with Dunn's multiple comparisons). 
GAD65

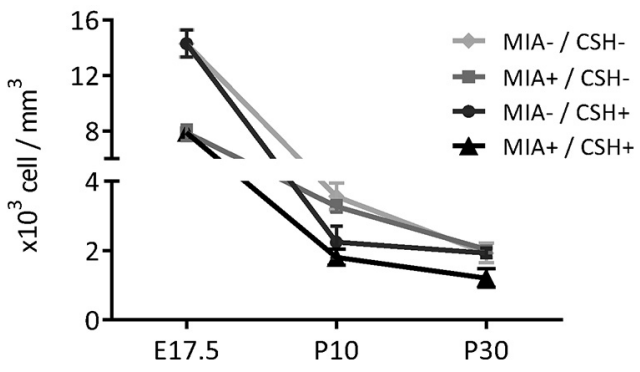

Figure 5. Effect of the multi-hit model on GAD65 positive cells density at E17.5, P10, and P30 in the PFC of mice treated with saline and reared under normoxia, subjected to with MIA and reared under normoxia, treated with saline and reared under $\mathrm{CSH}$, subjected to MIA and reared under $\mathrm{CSH}$. Values represent the mean $( \pm$ SEM) from at least seven animals out of at least two pregnancies; $* p<0.05$; $* * * p<0.001$ (two-way ANOVA, Tukey's multiple comparisons).

MIA to a second inflammatory response induced by hypoxia. These inflammatory markers had declined by P30 although interneuron loss persisted (Fig. $6 C-C^{\prime \prime}$ ).

\section{The multi-hit model alters working memory, cognitive flexibility, and social cognition}

To further define long-term behavioral alterations potentially linked to PFC GABAergic network deficits, neurobehavioral tests for working memory, cognitive flexibility and social cognition were performed.

Working memory was analyzed through the spontaneous alternation task in the $\mathrm{Y}$-maze, where the alternation level was significantly lower in mice exposed to MIA+/ $\mathrm{CSH}+$, and similar in mice exposed to MIA only (MIA+/ $\mathrm{CSH}--13 \%$, ns; MIA $+/ \mathrm{CSH}+-20 \% p<0.001$; Fig. $7 A$ ). This working memory deficit was confirmed in the Barnes maze test where the repeated investigation of previously explored holes was significantly higher in $\mathrm{MIA}+/ \mathrm{CSH}+$ animals $(+47 \% p<0.01$; Fig. $7 B)$, while the number of arm entries and nose-pokes remained stable across groups (Extended Data Fig. 7-1A,B).

Cognitive flexibility was examined using the reversallearning task of the water T-maze. No difference was observed for learning the initial location of the platform (Fig. 7C). In contrast, during the reversal learning phase, $\mathrm{MIA}+/ \mathrm{CSH}+$ mice required more time to learn the new location, with lower performance on days 2 and 3 (day 2 , $-35 \%, p<0.05$; day $3,-59 \%, p<0.05$; Fig. $7 D$ ). No significant difference was observed between groups by day 4 (Fig. 7D).

Social cognition was evaluated with social preference and novelty in the three-chamber test. During social preference, all the groups spent $>70 \%$ of the time with the conspecific animal (Fig. 7E). A similar pattern was observed during social novelty testing, where groups spent more time with the unfamiliar mouse (Fig. 7F). However, although $\mathrm{MIA}+/ \mathrm{CSH}+$ mice discriminate between the unfamiliar and familiar animal, they spent significantly less time interacting with the unfamiliar animal compared to controls $(-12 \% p<0.05$; Fig. $7 F)$ and exhibited decreased total interaction time $(-26 \% p<0.05$; Fig. $7 G)$.
No significant difference was observed for activity and anxiety in the open-field (Extended Data Fig. 7-1C-E) or for repetitive behavior with the marble burying test (Extended Data Fig. 7-1F).

Overall, this new multi-hit mouse model decreases several subtypes of interneurons in the ULs of the PFC and induces behavioral deficits characteristic of schizophrenia-like disorders. The observation of a pronounced decrease in the density of multiple interneuron subtypes in the human preterm brain samples examined here suggests that alterations of interneurons following extreme prematurity might be a risk factor for psychiatric disorders or other neurodevelopmental disabilities that can follow preterm birth.

\section{Discussion}

Elucidating the effects of perinatal insults on GABAergic interneuron development is critical to understanding the mechanistic role they play in the pathogenesis of neuropsychiatric disorders. While human glutamatergic neurogenesis is complete by 28 weeks of gestation (Malik et al., 2013), GABAergic progenitors persist in the ganglionic eminences through at least 35 weeks of gestation and continue to migrate into the cortex throughout the perinatal period (Sanai et al., 2011; Arshad et al., 2016; Paredes et al., 2016), suggesting that perinatal insults may be significant environmental factors predisposing preterm survivors to psychiatric disorders.

In the present study, the BA9 of one-month-old term and one-month term corrected-age very preterm infants were compared. A decrease in the density of both SST and CLB interneuron subtypes was seen in the ULs of the frontal cortex from these preterm infants. Human pathology studies remain limited, but our findings are consistent with prior studies showing altered interneuron numbers in preterm infants (aged from a few hours to a few weeks postpartum) in the white matter and subplate (Robinson et al., 2006), and in the cortical plate (Panda et al., 2018).

The human tissue used here comes from preterm donors who survived up to five months and were subjected to the adverse environment of prematurity for a significant period. While the insults that lead directly to death may have contributed to our findings, the immediate cause of death was similar in both the preterm and term infants (most commonly "sudden infant death syndrome," while confounding genetic or obviously infectious diagnoses were excluded). However, the possibility remains that the observed PFC interneuron deficit may be linked not only to chorioamnionitis and respiratory compromise but to a variety of perinatal insults, many of which remain undefined. Human data suggest that generation of interneurons continues well into the postnatal period (Yang et al., 2011; Arshad et al., 2016; Paredes et al., 2016) raising the possibility that human survivors of extreme prematurity could subsequently produce interneurons to compensate for the observed loss. Many preterm infants survive neurologically intact and this postmortem sampling may reflect a more compromised population or a delay in interneuron development that would have recovered. In the future, non-invasive methods that measure localized 
A
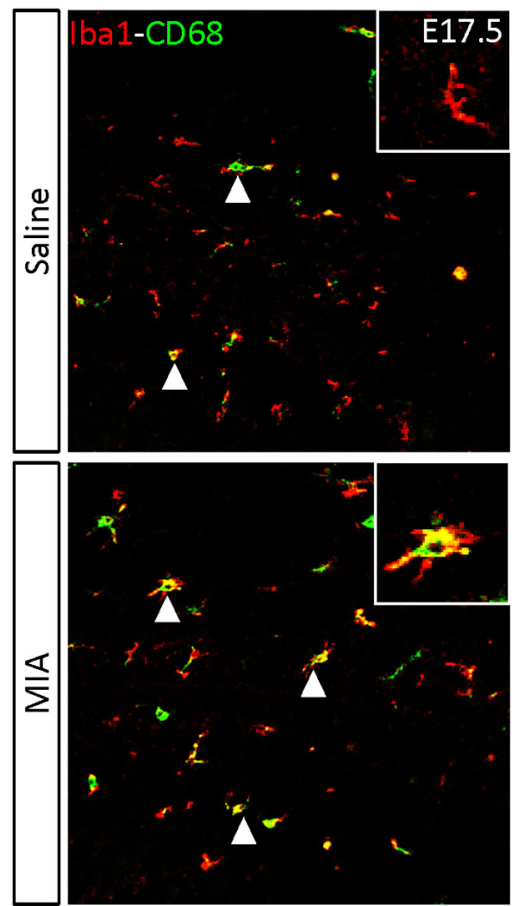

A'

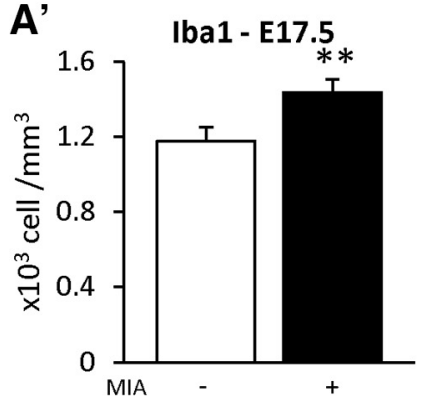

A"

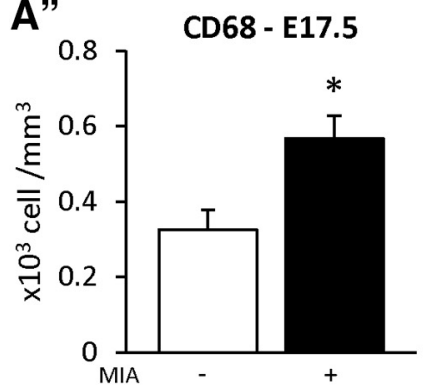

B
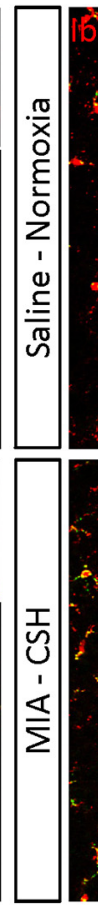

B
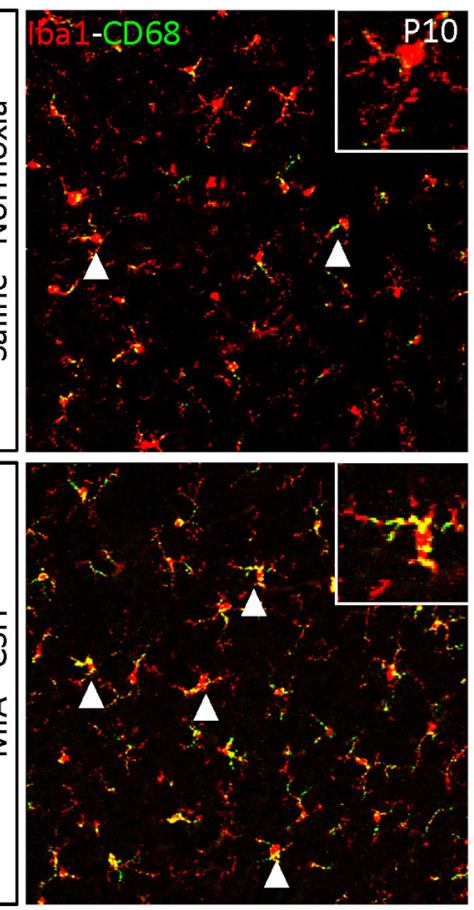

C
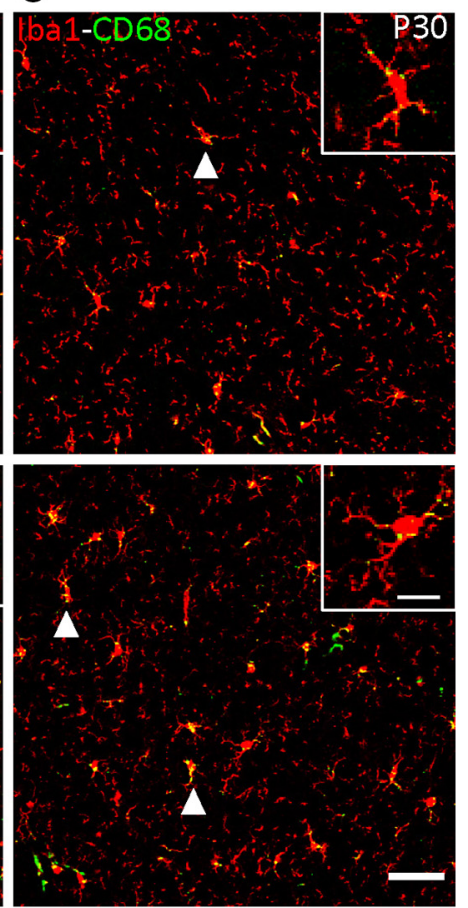

C'

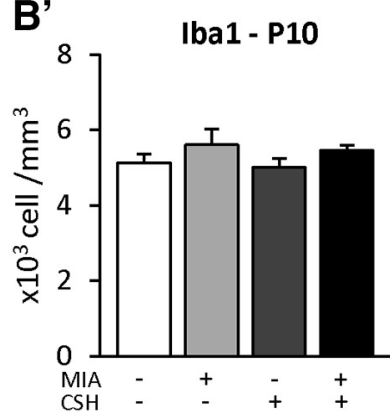

B"'

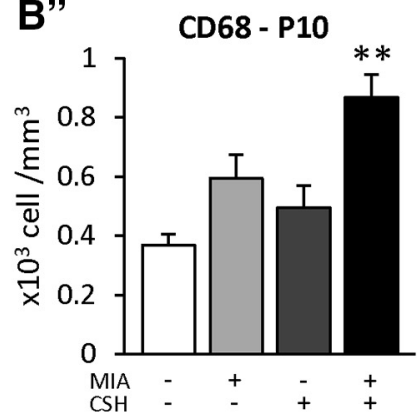

Iba1 - P30
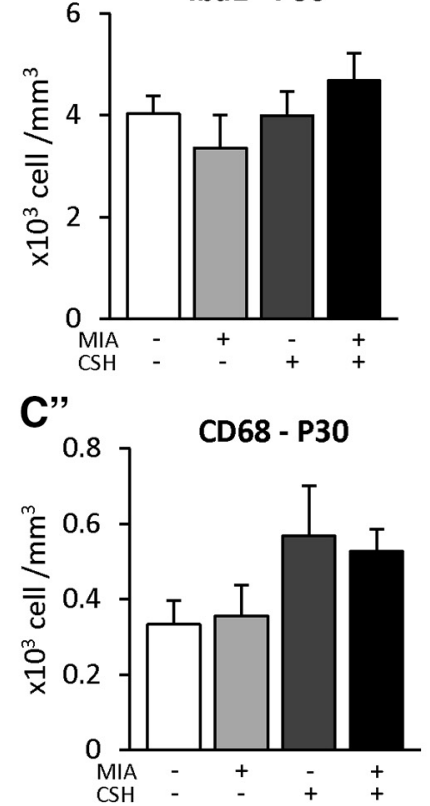

Figure 6. Effect of the multi-hit model on microglial density (Iba1) and activation (CD68) in the PFC at (A) E17.5 subjected to saline or MIA (injected with $150 \mu \mathrm{g} / \mathrm{kg}$ of LPS at E15.5 and E16.5), (B) P10, and (C) P30 mice treated with saline and reared under normoxia or subjected to MIA and reared under CSH. Arrowheads highlight cells positive for lba1 and CD68. Scale bar $=50 \mu \mathrm{m}$. Scale bar of

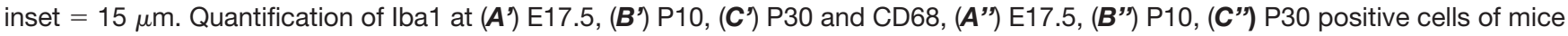
treated with saline and reared under normoxia, subjected to with MIA and reared under normoxia, treated with saline and reared under $\mathrm{CSH}$, subjected to MIA and reared under CSH. Values represent the mean ( \pm SEM) from five to six animals out two pregnancies. $\boldsymbol{A}^{\prime}$, $\boldsymbol{A}^{\prime \prime}, * p<0.05 ; * * p<0.01$ (Mann-Whitney); $\boldsymbol{B}^{\prime}-C^{\prime \prime}, * * p<0.01$ (Kruskal-Wallis test with Dunn's multiple comparisons).

GABA concentrations in living infants may help clarify these issues, but such techniques do not yet have the resolution required, so models must be used to better understand the progression of injury and underlying mechanisms.
Pairing two previously established methods (MIA and $\mathrm{CSH}$ ) created a novel model of preterm encephalopathy that more closely mimics this human pathology. Unlike other multi-hit models (Jantzie et al., 2014; Mallard and 
A

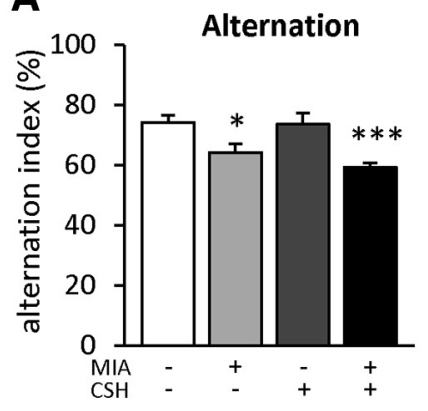

C

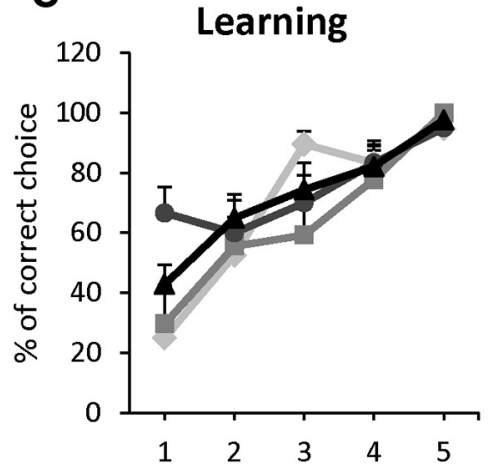

$\mathbf{E}$

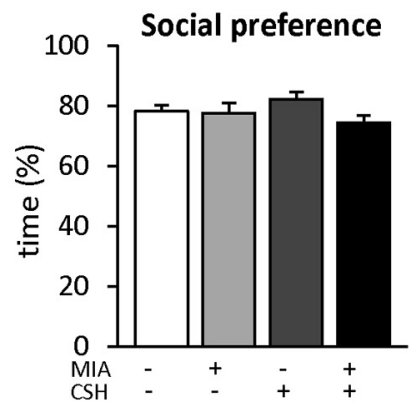

B

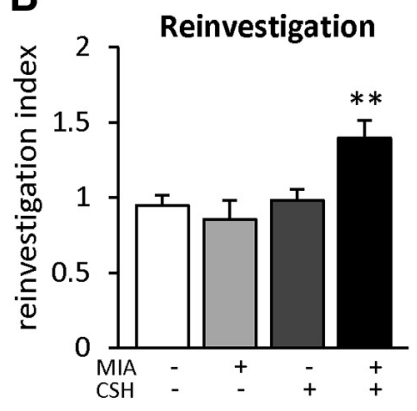

D

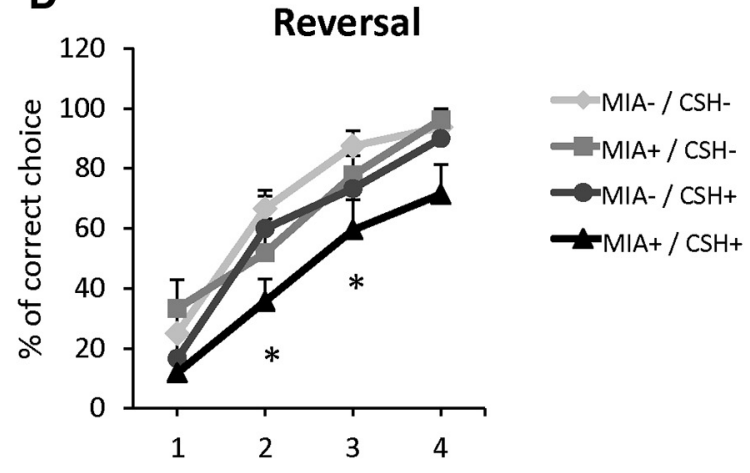

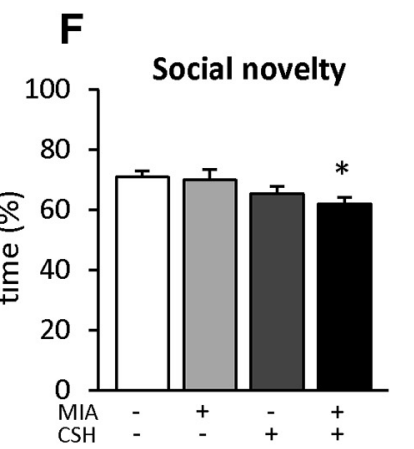

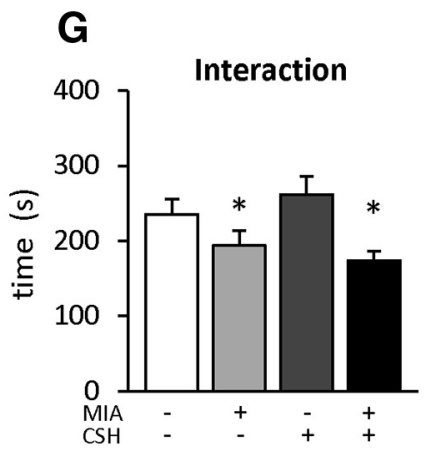

Figure 7. Behavioral characterization. Assessment of working memory with spontaneous alternation in the Y-maze, mice were allowed to freely explore the maze for $10 \mathrm{~min}$. A, Alternation index. Reinvestigation in the Barnes maze, mice were allowed to freely explore the maze for $10 \mathrm{~min}$. $\boldsymbol{B}$, Reinvestigation index. Assessment of learning and reversal learning in the water T-maze. Percentage of correct choice during $(\boldsymbol{C})$ the learning phase $(5 \mathrm{~d})$ and $(\boldsymbol{D})$ the reversal phase of the test $(4 \mathrm{~d})$. Assessment of social cognition in the three-chamber test. Percentage of time spent interacting between $(\boldsymbol{E})$ a conspecific stranger (S1) versus an object; $(\boldsymbol{F})$ a novel (S2) versus a familiar (S1) conspecific; $(\boldsymbol{G})$ total time spent to interacting with conspecifics strangers of P30 mice treated with saline and reared under normoxia, subjected to with MIA (injected with $150 \mu \mathrm{g} / \mathrm{kg}$ of LPS at E15.5 and E16.5) and reared under normoxia, treated with saline and reared under CSH, subjected to MIA and reared under CSH. Complementary information is presented in Extended Data Figure 7-1. Values represent the mean ( \pm SEM) from eight to twelve animals out of two pregnancies. $\boldsymbol{A}, \boldsymbol{B}, \boldsymbol{E}-\boldsymbol{G}, * p<0.05 ; * * p$ $<0.01 ; * * * p<0.001$ (one-way ANOVA with Holm-Sidak's multiple comparisons); $\boldsymbol{C}, \boldsymbol{D}, * p<0.05 ; * * p<0.01 ; * * * p<0.001$ (two-way ANOVA with Tukey's multiple comparisons).

Vexler, 2015), the use of MIA and CSH spans both preand postnatal periods, which is more representative of when preterm encephalopathy develops. Preclinical models of preterm brain injury are most successful when using multifactorial approaches that account for the complexity of the perinatal environment (Elovitz and Mrinalini, 2004; Manuel et al., 2017). The multi-hit mouse model was designed to investigate the effects of perinatal insults associated with preterm birth, producing a model in which later neurobehavioral disorders could be assessed.
Density of both GAD65 and GAD67 expressing cells was reduced, consistent with prior reports of prematurityrelated decreases in gad1 and gad2 transcripts, encoding GAD67 and GAD65, in the PFC (Richetto et al., 2014; Labouesse et al., 2015). The decrease observed here was specific to Layer II/III. In mice, cortical interneurons are generated in the MGE between E9.5 and E15.5 with a peak at E12.5, contributing to the cortical layers in an inside-out manner (Butt et al., 2007), and from the CGE between E12.5 and E18.5, with a peak at E16.5, contrib- 
uting to the superficial layers (Miyoshi et al., 2007, 2010; Torigoe et al., 2016). This data suggests that MIA altered the proliferation and migration of interneurons from the late MGE or from the CGE. A prior transcriptomic study using MIA shown down-regulation of transcripts involved in interneuron tangential migration including the Distalless $(D / x)$ family and both GAD isoforms (Oskvig et al., 2012), suggesting that impaired migration may also play a role in the findings observed in E17.5 cortex. Prenatal stress has also been shown to reduce the distribution of interneurons by impairing their migration (Stevens et al., 2013).

While PV neurons are known to be selectively altered by MIA (Canetta et al., 2016), the other interneuron subtypes have been less comprehensively studied in the context of perinatal brain injury. In mouse PFC, a reduced density and laminar distribution of PV is observed, as well as decreased numbers of SST, CLB, VIP, CRT, and NPY after combined MIA plus CSH. This is the first demonstration of decreased density of CLB, CRT, and NPY in a model of perinatal brain injury. A delay in maturation of these neurons may explain these effects, as suggested by a study in which hypoxia induced a decrease in PV, SST, and VIP immunoreactivity that partially recovered at later stages (Komitova et al., 2013). The data from the ganglionic eminences suggest decreased interneurogenesis following MIA, followed by possible maturation defects as a consequence of postnatal $\mathrm{CSH}$, supporting a combination of alterations on interneuron development.

MIA produces an early alteration of interneurogenesis followed by possible maturation defects as a consequence of postnatal $\mathrm{CSH}$, but the underlying mechanisms by which maternal inflammation or postnatal hypoxia perturbs brain development remain unknown. Blocking the actions of specific cytokines such as IL- $1 \beta$ prevents MIAinduced behavioral and physiologic consequences in mouse offspring, suggesting a role for pro-inflammatory cytokines in the process (Girard et al., 2010). In support of this, in the multi-hit model, a transient activation of microglial cells is showed after MIA, which is significantly enhanced by later $\mathrm{CSH}$. These findings, along with a recent report in a different mixed model (Zhou et al., 2017), highlight the extension of MIA-induced inflammatory response by $\mathrm{CSH}$, suggesting that postnatal insults potentiate abnormalities caused by in utero inflammation to permanently alter brain development.

To further define long-term behavioral alterations potentially linked to GABAergic network deficits in the PFC, a battery of neurobehavioral tests was performed. The multi-hit model of preterm brain injury induced deficits in working memory, cognitive flexibility and social interaction. Direct alterations of excitatory and inhibitory balance within the PFC have a strong effect on social motivation, predominantly mediated by PV and SST interneuron subtypes (Bicks et al., 2015), potentially underlying the deficits seen in social novelty and social interaction.

Alterations in working memory have been extensively discussed in the context of psychiatric disorders. MIA, a known cause of such disorders, has been shown to impair working memory in offspring (Murray et al., 2017). Addi- tionally, specific lesion of PV neurons in the PFC produces deficits in working memory and cognitive flexibility (Murray et al., 2015). Involvement of SST interneurons has also been demonstrated, although PV and SST interneurons show distinct contributions to PFC circuit dynamics underlying working memory (Kim et al., 2016). Impaired working memory in the multi-hit model may be associated with reduced GABAergic transmission by PV and SST interneurons in the adult PFC, but further investigations are needed to directly link specific interneuron losses with the observed behavioral phenotypes. Interestingly, lesion of the PFC or complete disruption of $\mathrm{GABA}_{A}$-receptormediated inhibition in the PFC by bicuculline infusion has been shown to recapitulate the behavioral deficits induced by the multi-hit model (Auger and Floresco, 2014; Hernan et al., 2014; Murray et al., 2015) supporting the hypothesis that the observed interneuron loss could cause the measured behavioral deficits.

In contrast to prior studies, here MIA alone did not impair working memory. This difference may stem from uses of lower LPS doses or timing of administration (Meyer et al., 2008). On the other hand, perinatal hypoxia alone induces impairments in associative learning, spatial memory, and long-term social memory that have been linked with white matter deficits (Cengiz et al., 2011; Lan et al., 2011; Salmaso et al., 2012). White matter injury has been mechanistically linked to interneuron deficits because interneurons promote oligodendrocytes development (Voronova et al., 2017), with hypoxic interneuron loss potentially contributing to impaired myelination.

Abnormalities in cortical interneurons have been broadly associated with cognitive deficits in the context of psychiatric disorders. The reduction of multiple interneuron subtypes in this model is consistent with prior observations in patients with schizophrenia. This pathology is also commonly cited with changes in GABA systemrelated transcripts, with altered expression of GABAsynthesizing enzymes (GAD65 and GAD67), GABA transporter systems and interneuron markers (SST, NPY, CLB, RLN, and cholecystokinin) reported (Hashimoto et al., 2003, 2008a,b; Maldonado-Avilés et al., 2009; Mellios et al., 2009; Volk et al., 2012). In this model, the potentiation of inflammation by postnatal CSH may increase the risk of psychiatric-related neurobehavioral deficits by producing latent inflammation with microglial activation across a critical developmental time (Meyer et al., 2011). Whether other more subtle indicators of latent inflammation persist into adulthood after the microglial activation subsides, as has been suggested for human autism spectrum disorders and schizophrenia (Meyer et al., 2011), remains to be explored. While the mechanistic links between loss of specific PFC interneurons and specific psychiatric deficits in both mouse and human need to be further investigated, the observed deficits are consistent with the cognitive (working memory and cognitive flexibility) and negative symptoms (social dysfunction) of schizophrenia. Thus, this model provides new opportunities to interrogate the molecular mechanisms that link perinatal insults, interneuron deficits and later neuropsychiatric risk. 


\section{References}

Adams-Chapman I, Stoll BJ (2006) Neonatal infection and long-term neurodevelopmental outcome in the preterm infant. Curr Opin Infect Dis 19:290-297. CrossRef Medline

Arpino C, Compagnone E, Montanaro ML, Cacciatore D, De Luca A, Cerulli A, Di Girolamo S, Curatolo P (2010) Preterm birth and neurodevelopmental outcome: a review. Childs Nerv Syst 26: 1139-1149. CrossRef Medline

Arshad A, Vose LR, Vinukonda G, Hu F, Yoshikawa K, Csiszar A, Brumberg JC, Ballabh P (2016) Extended production of cortical interneurons into the third trimester of human gestation. Cereb Cortex 26:2242-2256. CrossRef Medline

Auger ML, Floresco SB (2014) Prefrontal cortical GABA modulation of spatial reference and working memory. Int J Neuropsychopharmacol 18:pyu013. CrossRef Medline

Bicks LK, Koike H, Akbarian S, Morishita H (2015) Prefrontal cortex and social cognition in mouse and man. Front Psychol 6:1805. CrossRef Medline

Blencowe H, Cousens S, Chou D, Oestergaard M, Say L, Moller AB, Kinney M, Lawn J (2013) Born too soon: the global epidemiology of 15 million preterm births. Reprod Health 10[Suppl 1]:S2. CrossRef Medline

Butt SJ, Cobos I, Golden J, Kessaris N, Pachnis V, Anderson S (2007) Transcriptional regulation of cortical interneuron development. J Neurosci 27:11847-11850. CrossRef Medline

Canetta S, Bolkan S, Padilla-Coreano N, Song LJ, Sahn R, Harrison NL, Gordon JA, Brown A, Kellendonk C (2016) Maternal immune activation leads to selective functional deficits in offspring parvalbumin interneurons. Mol Psychiatry 21:956-968. CrossRef Medline

Carpentier PA, Haditsch U, Braun AE, Cantu AV, Moon HM, Price $\mathrm{RO}$, Anderson MP, Saravanapandian V, Ismail K, Rivera M, Weimann JM, Palmer TD (2013) Stereotypical alterations in cortical patterning are associated with maternal illness-induced placental dysfunction. J Neurosci 33:16874-16888. CrossRef Medline

Cengiz P, Uluc K, Kendigelen P, Akture E, Hutchinson E, Song C, Zhang L, Lee J, Budoff GE, Meyerand E, Sun D, Ferrazzano P (2011) Chronic neurological deficits in mice after perinatal hypoxia and ischemia correlate with hemispheric tissue loss and white matter injury detected by MRI. Dev Neurosci 33:270-279. CrossRef Medline

Elovitz MA, Mrinalini C (2004) Animal models of preterm birth. Trends Endocrinol Metab 15:479-487. CrossRef Medline

Fagel DM, Ganat Y, Cheng E, Silbereis J, Ohkubo Y, Ment LR, Vaccarino FM (2009) Fgfr1 is required for cortical regeneration and repair after perinatal hypoxia. J Neurosci 29:1202-1211. CrossRef Medline

Fatemi SH, Reutiman TJ, Folsom TD, Thuras PD (2009) GABA(A) receptor downregulation in brains of subjects with autism. J Autism Dev Disord 39:223-230. CrossRef Medline

Filice F, Vorckel KJ, Sungur AO, Wohr M, Schwaller B (2016) Reduction in parvalbumin expression not loss of the parvalbuminexpressing GABA interneuron subpopulation in genetic parvalbumin and shank mouse models of autism. Mol Brain 9:10. CrossRef Medline

Girard S, Tremblay L, Lepage M, Sébire G (2010) IL-1 receptor antagonist protects against placental and neurodevelopmental defects induced by maternal inflammation. J Immunol 184:39974005. CrossRef Medline

Gogolla N, Leblanc JJ, Quast KB, Südhof TC, Fagiolini M, Hensch TK (2009) Common circuit defect of excitatory-inhibitory balance in mouse models of autism. J Neurodev Disord 1:172-181. CrossRef Medline

Habl G, Schmitt A, Zink M, von Wilmsdorff M, Yeganeh-Doost $P$, Jatzko A, Schneider-Axmann T, Bauer M, Falkai P (2012) Decreased reelin expression in the left prefrontal cortex (BA9) in chronic schizophrenia patients. Neuropsychobiology 66:57-62. CrossRef Medline
Hashemi E, Ariza J, Rogers H, Noctor SC, Martinez-Cerdeno V (2017) The number of parvalbumin-expressing interneurons is decreased in the medial prefrontal cortex in autism. Cereb Cortex 27:19311943. CrossRef Medline

Hashimoto T, Volk DW, Eggan SM, Mirnics K, Pierri JN, Sun Z, Sampson AR, Lewis DA (2003) Gene expression deficits in a subclass of GABA neurons in the prefrontal cortex of subjects with schizophrenia. J Neurosci 23:6315-6326. CrossRef Medline

Hashimoto T, Bazmi HH, Mirnics K, Wu Q, Sampson AR, Lewis DA (2008a) Conserved regional patterns of GABA-related transcript expression in the neocortex of subjects with schizophrenia. Am J Psychiatry 165:479-489. CrossRef Medline

Hashimoto T, Arion D, Unger T, Maldonado-Avilés JG, Morris HM, Volk DW, Mirnics K, Lewis DA (2008b) Alterations in GABA-related transcriptome in the dorsolateral prefrontal cortex of subjects with schizophrenia. Mol Psychiatry 13:147-161. CrossRef Medline

Hernan AE, Alexander A, Jenks KR, Barry J, Lenck-Santini PP, Isaeva E, Holmes GL, Scott RC (2014) Focal epileptiform activity in the prefrontal cortex is associated with long-term attention and sociability deficits. Neurobiol Dis 63:25-34. CrossRef Medline

Jantzie LL, Corbett CJ, Berglass J, Firl DJ, Flores J, Mannix R, Robinson S (2014) Complex pattern of interaction between in utero hypoxia-ischemia and intra-amniotic inflammation disrupts brain development and motor function. J Neuroinflammation 11:131. CrossRef Medline

Johnson S, Marlow N (2011) Preterm birth and childhood psychiatric disorders. Pediatr Res 69:11r-18r. CrossRef Medline

Kim D, Jeong H, Lee J, Ghim JW, Her ES, Lee SH, Jung MW (2016) Distinct roles of parvalbumin- and somatostatin-expressing interneurons in working memory. Neuron 92:902-915. CrossRef Medline

Knuesel I, Chicha L, Britschgi M, Schobel SA, Bodmer M, Hellings JA, Toovey S, Prinssen EP (2014) Maternal immune activation and abnormal brain development across CNS disorders. Nat Rev Neurol 10:643-660. CrossRef Medline

Komitova M, Xenos D, Salmaso N, Tran KM, Brand T, Schwartz ML, Ment L, Vaccarino FM (2013) Hypoxia-induced developmental delays of inhibitory interneurons are reversed by environmental enrichment in the postnatal mouse forebrain. J Neurosci 33: 13375-13387. CrossRef Medline

Kwon SH, Scheinost D, Lacadie C, Benjamin J, Myers EH, Qiu M, Schneider KC, Rothman DL, Constable RT, Ment LR (2014) GABA, resting-state connectivity and the developing brain. Neonatology 106:149-155. CrossRef Medline

Labouesse MA, Dong E, Grayson DR, Guidotti A, Meyer U (2015) Maternal immune activation induces GAD1 and GAD2 promoter remodeling in the offspring prefrontal cortex. Epigenetics 10:11431155. CrossRef Medline

Lan WC, Priestley M, Mayoral SR, Tian L, Shamloo M, Penn AA (2011) Sex-specific cognitive deficits and regional brain volume loss in mice exposed to chronic, sublethal hypoxia. Pediatr Res 70:15-20. CrossRef Medline

Lombardo MV, Moon HM, Su J, Palmer TD, Courchesne E, Pramparo T (2017) Maternal immune activation dysregulation of the fetal brain transcriptome and relevance to the pathophysiology of autism spectrum disorder. Mol Psychiatry 23:1001-1013. CrossRef Medline

López-Bendito G, Sturgess K, Erdélyi F, Szabó G, Molnár Z, Paulsen O (2004) Preferential origin and layer destination of GAD65-GFP cortical interneurons. Cereb Cortex 14:1122-1133. CrossRef Medline

Maldonado-Avilés JG, Curley AA, Hashimoto T, Morrow AL, Ramsey AJ, O'Donnell P, Volk DW, Lewis DA (2009) Altered markers of tonic inhibition in the dorsolateral prefrontal cortex of subjects with schizophrenia. Am J Psychiatry 166:450-459. CrossRef Medline

Malik S, Vinukonda G, Vose LR, Diamond D, Bhimavarapu BB, Hu F, Zia MT, Hevner R, Zecevic N, Ballabh P (2013) Neurogenesis continues in the third trimester of pregnancy and is suppressed by premature birth. J Neurosci 33:411-423. CrossRef Medline 
Mallard C, Vexler ZS (2015) Modeling ischemia in the immature brain: how translational are animal models? Stroke 46:3006-3011. CrossRef Medline

Manuel CR, Ashby CR, Reznik SE (2017) Discrepancies in animal models of preterm birth. Curr Pharm Des 23:6142-6148. CrossRef Medline

Marin O (2012) Interneuron dysfunction in psychiatric disorders. Nat Rev Neurosci 13:107-120. CrossRef Medline

Mayoral SR, Omar G, Penn AA (2009) Sex differences in a hypoxia model of preterm brain damage. Pediatr Res 66:248-253. CrossRef Medline

Meechan DW, Tucker ES, Maynard TM, LaMantia AS (2009) Diminished dosage of 22q11 genes disrupts neurogenesis and cortical development in a mouse model of 22q11 deletion/DiGeorge syndrome. Proc Natl Acad Sci USA 106:16434-16445. CrossRef Medline

Meldrum SJ, Strunk T, Currie A, Prescott SL, Simmer K, Whitehouse AJ (2013) Autism spectrum disorder in children born preterm-role of exposure to perinatal inflammation. Front Neurosci 7:123. CrossRef Medline

Mellios N, Huang HS, Baker SP, Galdzicka M, Ginns E, Akbarian S (2009) Molecular determinants of dysregulated GABAergic gene expression in the prefrontal cortex of subjects with schizophrenia. Biol Psychiatry 65:1006-1014. CrossRef Medline

Meyer U, Nyffeler M, Yee BK, Knuesel I, Feldon J (2008) Adult brain and behavioral pathological markers of prenatal immune challenge during early/middle and late fetal development in mice. Brain Behav Immun 22:469-486. CrossRef Medline

Meyer U, Feldon J, Dammann O (2011) Schizophrenia and autism: both shared and disorder-specific pathogenesis via perinatal inflammation? Pediatr Res 69:26r-33r. CrossRef Medline

Miyoshi G, Butt SJ, Takebayashi H, Fishell G (2007) Physiologically distinct temporal cohorts of cortical interneurons arise from telencephalic Olig2-expressing precursors. J Neurosci 27:7786-7798. CrossRef Medline

Miyoshi G, Hjerling-Leffler J, Karayannis T, Sousa VH, Butt SJ, Battiste J, Johnson JE, Machold RP, Fishell G (2010) Genetic fate mapping reveals that the caudal ganglionic eminence produces a large and diverse population of superficial cortical interneurons. J Neurosci 30:1582-1594. CrossRef Medline

Murray AJ, Woloszynowska-Fraser MU, Ansel-Bollepalli L, Cole KL, Foggetti A, Crouch B, Riedel G, Wulff P (2015) Parvalbuminpositive interneurons of the prefrontal cortex support working memory and cognitive flexibility. Sci Rep 5:16778. CrossRef Medline

Murray BG, Davies DA, Molder JJ, Howland JG (2017) Maternal immune activation during pregnancy in rats impairs working memory capacity of the offspring. Neurobiol Learn Mem 141:150-156. CrossRef Medline

Oskvig DB, Elkahloun AG, Johnson KR, Phillips TM, Herkenham M (2012) Maternal immune activation by LPS selectively alters specific gene expression profiles of interneuron migration and oxidative stress in the fetus without triggering a fetal immune response. Brain Behav Immun 26:623-634. CrossRef Medline

Panda S, Dohare P, Jain S, Parikh N, Singla P, Mehdizadeh R, Klebe DW, Kleinman GM, Cheng B, Ballabh P (2018) Estrogen treatment reverses prematurity-induced disruption in cortical interneuron population. J Neurosci 38:7378-7391. CrossRef Medline

Paredes MF, James D, Gil-Perotin S, Kim H, Cotter JA, Ng C, Sandoval K, Rowitch DH, Xu D, McQuillen PS, Garcia-Verdugo JM, Huang EJ, Alvarez-Buylla A (2016) Extensive migration of young neurons into the infant human frontal lobe. Science 354: aaf7073. CrossRef Medline

Richetto J, Calabrese F, Riva MA, Meyer U (2014) Prenatal immune activation induces maturation-dependent alterations in the prefrontal GABAergic transcriptome. Schizophr Bull 40:351-361. CrossRef Medline

Robinson S, Li Q, Dechant A, Cohen ML (2006) Neonatal loss of gamma-aminobutyric acid pathway expression after human perinatal brain injury. J Neurosurg 104:396-408. CrossRef Medline
Salmaso N, Silbereis J, Komitova M, Mitchell P, Chapman K, Ment LR, Schwartz ML, Vaccarino FM (2012) Environmental enrichment increases the GFAP+ stem cell pool and reverses hypoxiainduced cognitive deficits in juvenile mice. J Neurosci 32:89308939. CrossRef Medline

Salmaso N, Jablonska B, Scafidi J, Vaccarino FM, Gallo V (2014) Neurobiology of premature brain injury. Nat Neurosci 17:341-346. CrossRef Medline

Salmaso N, Dominguez M, Kravitz J, Komitova M, Vaccarino FM, Schwartz ML (2015) Contribution of maternal oxygenic state to the effects of chronic postnatal hypoxia on mouse body and brain development. Neurosci Lett 604:12-17. CrossRef Medline

Samaco RC, Hogart A, LaSalle JM (2005) Epigenetic overlap in autism-spectrum neurodevelopmental disorders: MECP2 deficiency causes reduced expression of UBE3A and GABRB3. Hum Mol Genet 14:483-492. CrossRef Medline

Sanai N, Nguyen T, Ihrie RA, Mirzadeh Z, Tsai HH, Wong M, Gupta N, Berger MS, Huang E, Garcia-Verdugo JM, Rowitch DH, AlvarezBuylla A (2011) Corridors of migrating neurons in the human brain and their decline during infancy. Nature 478:382-386. CrossRef Medline

Scafidi J, Hammond TR, Scafidi S, Ritter J, Jablonska B, Roncal M, Szigeti-Buck K, Coman D, Huang Y, McCarter RJ Jr, Hyder F, Horvath TL, Gallo V (2014) Intranasal epidermal growth factor treatment rescues neonatal brain injury. Nature 506:230-234. CrossRef Medline

Skorput AG, Gupta VP, Yeh PW, Yeh HH (2015) Persistent interneuronopathy in the prefrontal cortex of young adult offspring exposed to ethanol in utero. J Neurosci 35:10977-10988. CrossRef Stevens HE, Su T, Yanagawa Y, Vaccarino FM (2013) Prenatal stress delays inhibitory neuron progenitor migration in the developing neocortex. Psychoneuroendocrinology 38:509-521. CrossRef Medline

Sugranyes G, Kyriakopoulos M, Corrigall R, Taylor E, Frangou S (2011) Autism spectrum disorders and schizophrenia: metaanalysis of the neural correlates of social cognition. PLoS One 6:e25322. CrossRef Medline

Takano T (2015) Interneuron dysfunction in syndromic autism: recent advances. Dev Neurosci 37:467-475. CrossRef Medline

Tooney PA, Chahl LA (2004) Neurons expressing calcium-binding proteins in the prefrontal cortex in schizophrenia. Prog Neuropsychopharmacol Biol Psychiatry 28:273-278. CrossRef Medline

Torigoe M, Yamauchi K, Kimura T, Uemura Y, Murakami F (2016) Evidence that the laminar fate of LGE/CGE-derived neocortical interneurons is dependent on their progenitor domains. J Neurosci 36:2044-2056. CrossRef Medline

Tremblay R, Lee S, Rudy B (2016) GABAergic interneurons in the neocortex: from cellular properties to circuits. Neuron 91:260-292. CrossRef Medline

Volk DW, Matsubara T, Li S, Sengupta EJ, Georgiev D, Minabe Y, Sampson A, Hashimoto T, Lewis DA (2012) Deficits in transcriptional regulators of cortical parvalbumin neurons in schizophrenia. Am J Psychiatry 169:1082-1091. CrossRef Medline

Voronova A, Yuzwa SA, Wang BS, Zahr S, Syal C, Wang J, Kaplan DR, Miller FD (2017) Migrating interneurons secrete fractalkine to promote oligodendrocyte formation in the developing mammalian brain. Neuron 94:500-516.e9. CrossRef Medline

Yang Z, Ming GL, Song H (2011) Postnatal neurogenesis in the human forebrain: from two migratory streams to dribbles. Cell Stem Cell 9:385-386. CrossRef Medline

Zhou Y, Huang X, Zhao T, Qiao M, Zhao X, Zhao M, Xu L, Zhao Y, Wu L, Wu K, Chen R, Fan M, Zhu L (2017) Hypoxia augments LPSinduced inflammation and triggers high altitude cerebral edema in mice. Brain Behav Immun 64:266-275. CrossRef Medline

Zonouzi M, Scafidi J, Li P, McEllin B, Edwards J, Dupree JL, Harvey L, Sun D, Hübner CA, Cull-Candy SG, Farrant M, Gallo V (2015) GABAergic regulation of cerebellar NG2 cell development is altered in perinatal white matter injury. Nat Neurosci 18:674-682. CrossRef Medline 